\title{
Airborne Multisensor Pod System (AMPS) Data Management Overview
}

\author{
J. D. Wiberg \\ D. K. Blough \\ W. R. Daugherty \\ L. H. Gerhardstein \\ J. A. Hucks \\ W. D. Meitzler \\ R. B. Melton \\ S. V. Shoemaker
}

September 1994

Prepared for

the U.S. Department of Energy

under Contract DE-AC06-76RLO 1830

Pacific Northwest Laboratory

Richland, Washington 99352 


\section{DISCLAIMER}

This report was prepared as an account of work sponsored by an agency of the United States Government. Neither the United States Government nor any agency thereof, nor any of their employees, make any warranty, express or implied, or assumes any legal liability or responsibility for the accuracy, completeness, or usefulness of any information, apparatus, product, or process disclosed, or represents that its use would not infringe privately owned rights. Reference herein to any specific commercial product, process, or service by trade name, trademark, manufacturer, or otherwise does not necessarily constitute or imply its endorsement, recommendation, or favoring by the United States Government or any agency thereof. The views and opinions of authors expressed herein do not necessarily state or reflect those of the United States Government or any agency thereof. 


\section{DISCLAIMER}

Portions of this document may be illegible in electronic image products. Images are produced from the best available original document. 


\section{Summary}

An overview of the Data Management Plan for the Airborne Multisensor Pod System (AMPS) program is provided in this document. The Pacific Northwest Laboratory (PNL) has been assigned responsibility of data management for the program, which includes defining procedures for data management and data quality assessment. Data management is defined as the process of planning, acquiring, organizing, qualifying and disseminating data. Described is the general approach to data management that PNL has developed. Summarized are the overall AMPS data management requirements and the plan for meeting those requirements. Specific requirements will be presented in followon documents.

The AMPS program was established by the U.S. Department of Energy (DOE), Office of Arms Control and Non-Proliferation (DOE/AN) and is integrated into the overall DOE AN-10.1 technology development program. Sensors used for collecting the data were developed under the on-site inspection, effluence analysis, and standoff sensor program, the AMPS program interacts with other technology programs of DOE/NN-20. This research will be conducted by both government and private industry. AMPS is a research and development program, and it is not intended for operational deployment, although the sensors and techniques developed could be used in follow-on operational systems.

The primary purpose of the AMPS is to collect high-quality multisensor data to be used in data fusion research on how to reduce interpretation problems associated with data overload and to derive better information than can be derived from any single sensor. Secondary objectives of the AMPS program are sensor development and technology demonstration.

To collect the data for the program, three wing-mounted pods containing instruments with sensors for collecting data will be flight certified on a U.S. Navy RP-3A aircraft. The DOE AMPS program uses a cross section of U.S. DOE national laboratory system to obtain the appropriate technical expertise needed to address the program mission. The following national laboratories are participants in the AMPS development: Sandia National Laboratories, Lawrence Livermore National Laboratories, and the Pacific Northwest Laboratory.

The following organizations are also contributing to the program: Remote Sensing Laboratory at Las Vegas, Nevada, which is responsible for the imaging pod; the Naval Air Warfare Center at Point Mugu, California, which will provide the pilots who will fly the RP-3A aircraft used to test the pods; Consulting Aerospace Engineers, which will certify air worthiness; and the Naval Air Systems Command (NAVAIR), which will review it.

The Savannah River Technical Center is also contributing to the AMPS program. Infotec Development, Inc., provides DOE project management support and liaison with the Navy. PNL is specifically responsible for identifying and analyzing data management requirements across the AMPS program and for providing guidance in implementing data management procedures. 
In general, data management for the AMPS project begins with the design of sensors and instruments to be installed in the pods, continues with the collection of data during missions, and concludes with the delivery of the data for use in research. Stages of the AMPS data management process include the following:

- in-flight data collection

- data transfer and backup

- data storage.

Within this process, PNL is to provide the infrastructure required for consistent and orderly planning, acquisition and distribution of AMPS-related information. This infrastructure must allow each participating organization to proceed independently with its research, yet provide a coherent set of data that can be rapidly distributed to the AMPS research community. 


\section{Glossary}

The following acronyms and terms are used in the AMPS program:

\begin{tabular}{|c|c|}
\hline AC-ITMS & Air Concentrator-Ion Trap Mass Spectrometer \\
\hline $\begin{array}{l}\text { ADC } \\
\text { AMPS }\end{array}$ & anolog-to-digital converter \\
\hline $\begin{array}{l}\text { AMPS } \\
\text { AMS }\end{array}$ & $\begin{array}{l}\text { Airborne Multisensor Pod System } \\
\text { Airborne Multispectral Scanner }\end{array}$ \\
\hline $\mathrm{amu}$ & atomic mass unit \\
\hline ANSI & American National Standards Institute \\
\hline API & application program interface \\
\hline $\mathrm{Ba}$ & barium \\
\hline BBS & computer bulletin board \\
\hline BUNO & Bureau Number \\
\hline CAE & Consulting Aerospace Engineers \\
\hline CASI & Compact Airborne Spectrographic Imager \\
\hline CCD & charge coupled device \\
\hline CD-ROM & Compact Disk - Read Only Memory \\
\hline CORBA & Common Object Request Broker Architecture \\
\hline COSE & Common Open Software Endorsement \\
\hline $\mathrm{CVC}$ & color video camera \\
\hline $\mathrm{cm}^{-1}$ & inversion centimeters \\
\hline DOE & U.S. Department of Energy \\
\hline DOE/AN & U.S. Department of Energy/Office of Arms Control and Non-Proliferation \\
\hline DOP & decision options paper \\
\hline DP & defense programs \\
\hline ECMA & European Computer Manufacturers Association \\
\hline EG\&G & EG\&G Corporation (formerly, Edgerton, Gernshausen, and Grier) \\
\hline EGS & Echelle Grating Spectrometer \\
\hline EMI & electromagnetic interface \\
\hline ESI & effluent species identification \\
\hline FAQ & frequently asked/answered questions \\
\hline FIPS & Federal Information Processing Standards \\
\hline FTP & file transfer protocol \\
\hline FLIR & Forward Looking Infrared \\
\hline GIS & geographic information system \\
\hline GOSIP & Government Open Systems Interconnection Profile \\
\hline GPS & global positioning system \\
\hline IDI & Infotec Development, Inc. \\
\hline IEEE & Institute of Electrical and Electronic Engineers \\
\hline IGe & intrinsic germanium \\
\hline INS & Inertial Navigation System \\
\hline
\end{tabular}




\begin{tabular}{|c|c|}
\hline InSb & indium antimonide \\
\hline IR & infrared \\
\hline IS & DOE Office of Intelligence and National Security \\
\hline ISO & International Standards Organization \\
\hline IS-20 & Office of Research and Development within DOE/IS \\
\hline ITMS & Trap Mass Spectrometer \\
\hline $\mathrm{Kr}$ & krypton \\
\hline $\mathrm{km}$ & kilometer \\
\hline LLL & Iow light level \\
\hline LLNL & Lawrence Livermore National Laboratory \\
\hline LSB & least significant byte \\
\hline $\mathrm{m}^{3}$ & cubic meters \\
\hline MIL & U.S. Military Standards \\
\hline $\min ^{-1}$ & inverse minutes \\
\hline MITI & Ministry of International Trade and Industry \\
\hline MS/MS & mass spectrometry/mass spectrometry (tandem Mass Spectrometry) \\
\hline MSB & most significant byte \\
\hline MSI & multisensor imaging \\
\hline NASA & National Aeronautics and Space Administration \\
\hline NATOPS & Navel Air Training and Operating Procedures Standardization \\
\hline NAVAIR & Navel Air Systems Command \\
\hline NAWC & Navel Air Warfare Center \\
\hline NIST & National Institute of Standards and Technology \\
\hline NOAA & National Oceanographic and Atmospheric Administration \\
\hline NWTR & Naval Western Test Range \\
\hline OSF & Open Software Foundation \\
\hline OSI & Open Systems Interconnection \\
\hline PI & program introduction documentation \\
\hline PMIS & project management information system \\
\hline PNL & Pacific Northwest Laboratory \\
\hline POC & point of contact \\
\hline POSIX & Portable Operating System Interfaces, IEEE \\
\hline $\mathrm{ppb}$ & parts per billion \\
\hline ppm & parts per million \\
\hline ppt & parts per trillion \\
\hline $\mathbf{R b}$ & rubidium \\
\hline ROMAC & remote optical measurement of airborne chemicals \\
\hline RSL & Remote Sensing Laboratory \\
\hline R-TARAC & Real-Time Airborne Radionuclide Analyzer and Vapor Collector \\
\hline SAR & Synthetic Aperture Radar \\
\hline SIG & System Integration Group \\
\hline SMPTE & Society of Motion Picture and Television Engineers \\
\hline SNL & Sandia National Laboratories \\
\hline
\end{tabular}


$\mathrm{Sr}$

SRTC

UI

USGC

UV

VDC

VTR

Vis

X3

Xopen

strontium

Savannah River Technology Center

UNIX International

United States Geological Survey

ultra-violet

volts direct current

video tele-recorder

visible

Accredited Standards Committee for Information Processing user (vendor group for promoting standards) 



\section{Contents}

Summary $\ldots \ldots \ldots \ldots \ldots \ldots \ldots \ldots \ldots \ldots \ldots \ldots \ldots \ldots \ldots \ldots$ iii

Glossary $\ldots \ldots \ldots \ldots \ldots \ldots \ldots \ldots \ldots \ldots \ldots \ldots \ldots \ldots \ldots \ldots \ldots$

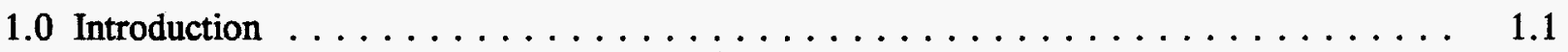

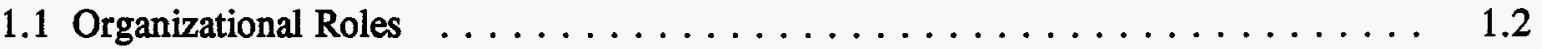

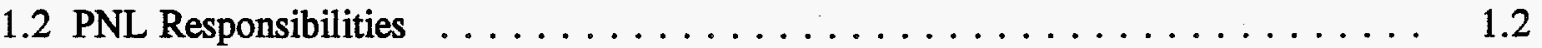

1.3 Document Purpose $\ldots \ldots \ldots \ldots \ldots \ldots \ldots \ldots \ldots \ldots \ldots \ldots \ldots$

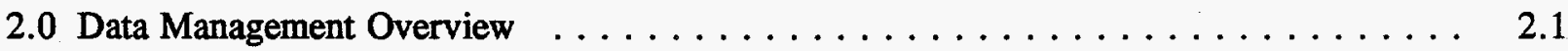

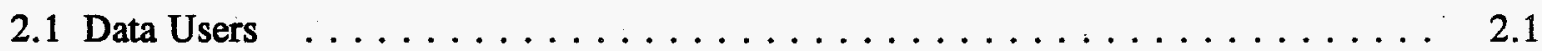

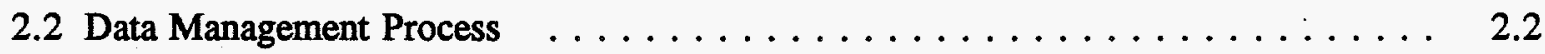

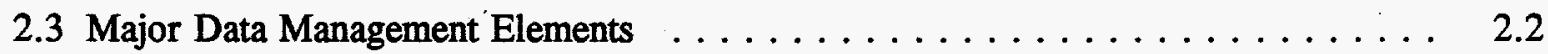

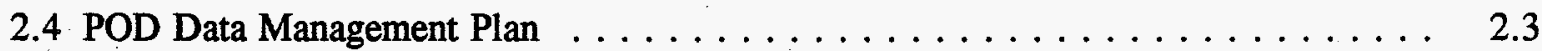

2.5 Data Collection Instruments $\ldots \ldots \ldots \ldots \ldots \ldots \ldots \ldots \ldots \ldots \ldots$

2.5.1 Characterization of AMPS Instruments $\ldots \ldots \ldots \ldots \ldots \ldots \ldots$

2.5.1.1 Synthetic Aperture Radar Pod $(\operatorname{Pod} 1) \ldots \ldots \ldots \ldots$

2.5.1.2 Multisensor Imaging $\operatorname{Pod}(\operatorname{Pod} 2) \ldots \ldots \ldots \ldots$

2.5.1.3 Effluent Species Identification Pod $(\operatorname{Pod} 3) \ldots \ldots \ldots$

2.5.1.4 Aircraft Instrumentation $\ldots \ldots \ldots \ldots \ldots \ldots \ldots \ldots \ldots \ldots$

2.5.2 Instrument Developers and Pod Integrators $\ldots \ldots \ldots \ldots \ldots$

2.5.3 AMPS Instrument Systems Constraints $\ldots \ldots \ldots \ldots \ldots \ldots$

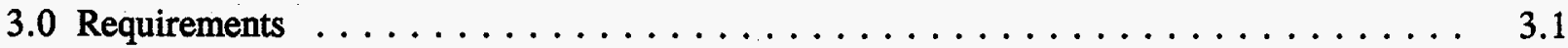

3.1 Data Management Infrastructure $\ldots \ldots \ldots \ldots \ldots \ldots \ldots \ldots \ldots \ldots \ldots \ldots$

3.1 .1 Mission Planning $\ldots \ldots \ldots \ldots \ldots \ldots \ldots \ldots \ldots \ldots \ldots \ldots \ldots \ldots$ 
3.1.2 AMPS Data Acquisition $\ldots \ldots \ldots \ldots \ldots \ldots \ldots \ldots \ldots \ldots \ldots \ldots \ldots \ldots$

3.1.3 Metadata $\ldots \ldots \ldots \ldots \ldots \ldots \ldots \ldots \ldots \ldots \ldots \ldots \ldots \ldots \ldots \ldots \ldots \ldots . .1$

3.1.4 Long-Term Data Storage $\ldots \ldots \ldots \ldots \ldots \ldots \ldots \ldots \ldots \ldots . .3$

3.1.4.1 Synthetic Aperture Radar Pod $(\operatorname{Pod} 1) \ldots \ldots \ldots \ldots \ldots .4 .4$

3.1.4.2 Multisensor Imaging Pod $(\operatorname{Pod} 2) \ldots \ldots \ldots \ldots \ldots \ldots .4 .4$

3.1.4.3 Effluent Species Identification Pod $(\operatorname{Pod} 3) \ldots \ldots \ldots \ldots . .4$

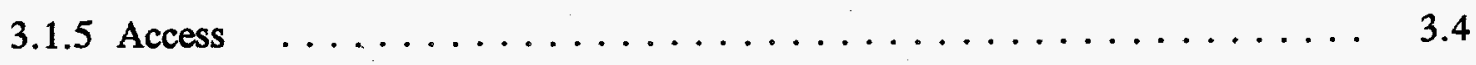

3.1.6 AMPS Data Quality $\ldots \ldots \ldots \ldots \ldots \ldots \ldots \ldots \ldots \ldots \ldots \ldots \ldots \ldots$

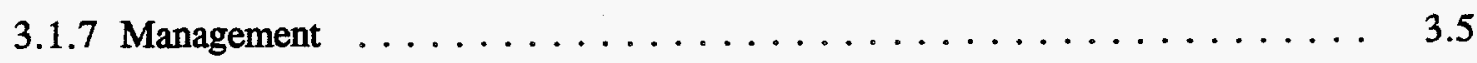

3.1.7.1 Time Synchronization $\ldots \ldots \ldots \ldots \ldots \ldots \ldots \ldots .3 .5$

3.1.7.2 Position Determination $\ldots \ldots \ldots \ldots \ldots \ldots \ldots \ldots \ldots .6$

3.1.7.3 Field of View of the Sensor $\ldots \ldots \ldots \ldots \ldots \ldots \ldots \ldots$

3.1.7.4 Information Logging $\ldots \ldots \ldots \ldots \ldots \ldots \ldots \ldots \ldots \ldots$

3.1 .8 Performance $\ldots \ldots \ldots \ldots \ldots \ldots \ldots \ldots \ldots \ldots \ldots \ldots \ldots \ldots \ldots \ldots \ldots$

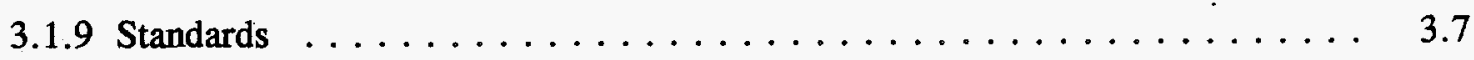

3.1.9.1 Data Format $\ldots \ldots \ldots \ldots \ldots \ldots \ldots \ldots \ldots \ldots \ldots \ldots .7$.

3.1.9.2 Data Dictionary $\ldots \ldots \ldots \ldots \ldots \ldots \ldots \ldots \ldots \ldots \ldots \ldots$

3.1.9.3 Information Catalog $\ldots \ldots \ldots \ldots \ldots \ldots \ldots \ldots \ldots .3 .7$

3.1.9.4 Quality Assurance $\ldots \ldots \ldots \ldots \ldots \ldots \ldots \ldots \ldots \ldots \ldots$

3.1 .10 Configuration Management $\ldots \ldots \ldots \ldots \ldots \ldots \ldots \ldots \ldots \ldots \ldots .8 .8$

3.2 Data Interchange Architecture $\ldots \ldots \ldots \ldots \ldots \ldots \ldots \ldots \ldots \ldots \ldots \ldots \ldots$

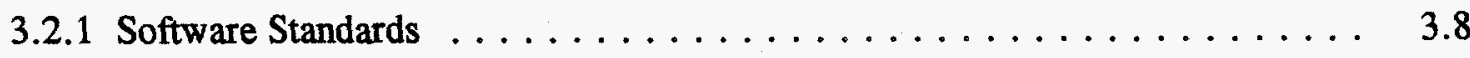

3.2.1.1 National Standards $\ldots \ldots \ldots \ldots \ldots \ldots \ldots \ldots \ldots .3 .9$

3.2.1.2 International Standards $\ldots \ldots \ldots \ldots \ldots \ldots \ldots \ldots \ldots .3 .9$ 
3.2.1.3 Standards User Groups $\ldots \ldots \ldots \ldots \ldots \ldots \ldots \ldots \ldots$

3.2.1.4 Open Standards $\ldots \ldots \ldots \ldots \ldots \ldots \ldots \ldots \ldots \ldots \ldots .3 .10$

3.2.1.5 De Facto Standards $\ldots \ldots \ldots \ldots \ldots \ldots \ldots \ldots \ldots \ldots$

3.2.2 Data Management Standards Criteria $\ldots \ldots \ldots \ldots \ldots \ldots \ldots \ldots .11$

3.2.2.1 File Systems $\ldots \ldots \ldots \ldots \ldots \ldots \ldots \ldots \ldots \ldots \ldots \ldots .11$

3.2.2.2 Data Archiving $\ldots \ldots \ldots \ldots \ldots \ldots \ldots \ldots \ldots \ldots \ldots \ldots \ldots \ldots .12$

3.2.2.3 On-Line Distribution $\ldots \ldots \ldots \ldots \ldots \ldots \ldots \ldots \ldots \ldots \ldots \ldots$

3.2.2.4 Off-Line Distribution $\ldots \ldots \ldots \ldots \ldots \ldots \ldots \ldots \ldots \ldots .3 .12$

3.2.2.5 Data Catalog $\ldots \ldots \ldots \ldots \ldots \ldots \ldots \ldots \ldots \ldots \ldots, 3.13$

3.2.2.6 Information Services $\ldots \ldots \ldots \ldots \ldots \ldots \ldots \ldots \ldots . .13$

3.2.3 Data File Standards Criteria $\ldots \ldots \ldots \ldots \ldots \ldots \ldots \ldots \ldots \ldots .13$

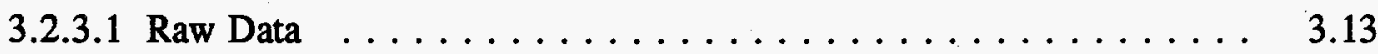

3.2.3.2 Image Processing and Graphics $\ldots \ldots \ldots \ldots \ldots \ldots \ldots \ldots .14$

3.2.3.3 Attributes and Metadata $\ldots \ldots \ldots \ldots \ldots \ldots \ldots \ldots \ldots$

3.2.3.4 Instrument Differences $\ldots \ldots \ldots \ldots \ldots \ldots \ldots \ldots \ldots \ldots .3 .14$

3.2.3.5 Self-Describing Data File $\ldots \ldots \ldots \ldots \ldots \ldots \ldots \ldots \ldots .3 .14$

3.2 .4 Selection Process $\ldots \ldots \ldots \ldots \ldots \ldots \ldots \ldots \ldots \ldots \ldots \ldots . \ldots \ldots$

3.2.4.1 Investigation $\ldots \ldots \ldots \ldots \ldots \ldots \ldots \ldots \ldots \ldots \ldots \ldots \ldots \ldots \ldots \ldots .14$

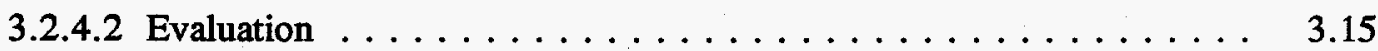

3.2.4.3 Needs of AMPS $\ldots \ldots \ldots \ldots \ldots \ldots \ldots \ldots \ldots \ldots \ldots \ldots$

3.2.4.4 Demonstration $\ldots \ldots \ldots \ldots \ldots \ldots \ldots \ldots \ldots \ldots \ldots \ldots \ldots \ldots \ldots .15$

3.2.4.5 Documentation $\ldots \ldots \ldots \ldots \ldots \ldots \ldots \ldots \ldots \ldots \ldots \ldots$

3.2.4.6 Adoption $\ldots \ldots \ldots \ldots \ldots \ldots \ldots \ldots \ldots \ldots \ldots \ldots \ldots \ldots$

Appendix A - AMPS Instrument Data Characteristics $\ldots \ldots \ldots \ldots \ldots \ldots \ldots \ldots$ A.1 
Figures

1.1 AMPS Data Management Plan $\ldots \ldots \ldots \ldots \ldots \ldots \ldots \ldots \ldots \ldots$ 


\subsection{Introduction}

An overview of the Data Management Plan for the Airborne Multisensor Pod System (AMPS) program is provided in this document. The Pacific Northwest Laboratory ${ }^{(a)}$ (PNL) has been assigned the responsibility of data management for the program, which includes defining procedures for data management and data quality assessment. Data management is defined as the process of planning, acquiring, organizing, qualifying and disseminating data.

The AMPS program was established by the U.S. Department of Energy (DOE), Office of Arms Control and Non-Proliferation (DOE/AN) and is integrated into the overall DOE AN-10.1 technology development program. Sensors used for collecting the data were developed under the on-site inspection, effluence analysis, and standoff sensor program, the AMPS program interacts with other technology programs of DOE/NN-20. This research will be conducted by both government and private industry. AMPS is a research and development program, and it is not intended for operational deployment, although the sensors and techniques developed could be used in follow-on operational systems.

For a complete description of the AMPS program, see "Airborne Multisensor Pod System (AMPS) Program Plan." (b)

The primary purpose of the AMPS is to collect high-quality multisensor data to be used in data fusion research to reduce interpretation problems associated with data overload and to derive better information than can be derived from any single sensor. To collect the data for the program, three wing-mounted pods containing instruments with sensors for collecting data will be flight certified on a U.S. Navy RP-3A aircraft.

Secondary objectives of the AMPS program are sensor development and technology demonstration. Pod system integrators and instrument developers will be interested in the performance of their deployed sensors and their supporting data acquisition equipment. A dialogue between the pod integrators and the data researchers is essential to facilitate further sensor/data acquisition enhancements.

Private industry may also become a user of this data, because data collected by the AMPS Program has the potential to be applied to commercial problems, such as pollution detection and control to wetlands and wildlife monitoring and protection. The applications of this type of technological effort are almost without bound. Therefore, in the future, certain AMPS data products and data reduction techniques may be made available to private industry via technology transfer.

(a) Pacific Northwest Laboratory is operated for the U.S. Department of Energy by Battelle Memorial Institute under Contract DE-AC06-76RL0 1830.

(b) U.S. Department of Energy (DOE). 1993. DOE NN-20, Washington, D.C. 


\subsection{Organizational Roles}

The DOE AMPS program uses a cross section of U.S. DOE national laboratory system to obtain the appropriate technical expertise needed to address the program mission. The following national laboratories are participants in the AMPS development effort: Sandia National Laboratories (SNL), Lawrence Livermore National Laboratories (LLNL), and the Pacific Northwest Laboratory (PNL).

The following organizations are also contributing to the program: Remote Sensing Laboratory (RSL) at Las Vegas, Nevada, which is responsible for the imaging pod; the Naval Air Warfare Center (NAWC) at Point Mugu, California, which will provide the pilots who will fly the RP-3A aircraft used to test the pods; Consulting Aerospace Engineers (CAE), which will certify air worthiness; and the Naval Air Systems Command (NAVAIR), which will review it.

The Savannah River Technical Center (SRTC) is also involved in the development effort. Infotec Development, Inc. (IDI); provides DOE project management support and liaison with the Navy. PNL is specifically responsible for identifying and analyzing data management requirements across the AMPS program and for providing guidance in implementing data management procedures.

\subsection{PNL Responsibilities}

In general, data management for the AMPS project begins with the design of sensors and instruments to be installed in the pods, continues with the collection of data during missions, and concludes with the delivery of the data for use in research. Stages of the AMPS data management process include the following:

- in-flight data collection

- data transfer and backup

- data storage.

Within this process, PNL is to provide the infrastructure required for consistent and orderly planning, acquisition and distribution of AMPS-related information. This infrastructure must allow each participating organization to proceed independently with its research, yet provide a coherent set of data that can be rapidly distributed to the AMPS research community. 
PNL's data management responsibilities include the following:

- formulating plans and procedures for managing sensor data from the AMPS instruments

- ensuring the acquisition and management of accompanying metadata, i.e., data that identifies the circumstances and conditions under which AMPS data is collected

- providing methods to assess the quality of AMPS data.

Specific AMPS program data management procedures will be developed from a requirements analysis. PNL will also investigate techniques for automated assessments of AMPS data quality and will recommend specific techniques to the program. Finally, PNL will investigate alternatives, such as Compact Disk-Read Only Memory (CD-ROM) production for distributing AMPS data sets and make recommendations to the program.

\subsection{Document Purpose}

The purpose of this document is to describe the general approach to data management that PNL has developed for the AMPS program. The document summarizes the overall AMPS data management requirements and presents the plan for meeting those requirements. Specific requirements will be presented in follow-on documents.

This is a living document that will be revised and updated as necessary over the course of the program. This document, as well as ones containing detailed plans, will be under change control. The official point of contact for requesting changes is Wayne Meitzler, PNL, 509-375-3718 and FAX (509) 375-3641. 


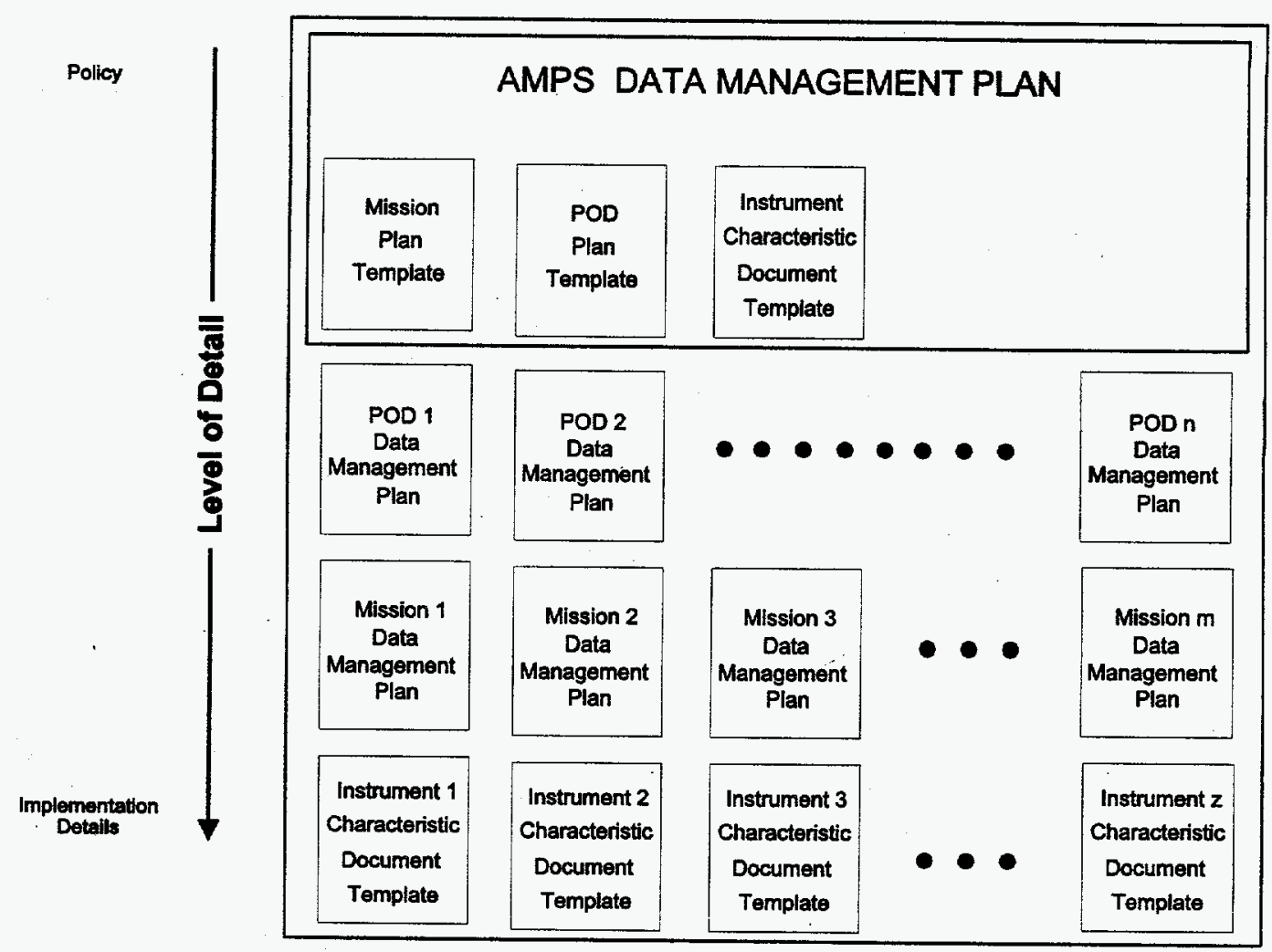

Figure 1.1. AMPS Data Management Plan 


\subsection{Data Management Overview}

As stated in the introduction, data management is defined as the process of acquiring, organizing, qualifying and disseminating data. The AMPS Data Management Plan applies to all AMPS data acquired during missions and metadata related to that data. AMPS data is defined as all data acquired through AMPS-designated instruments. These data include raw data, calibration data, and support data, i.e., metadata, which identifies the circumstances and conditions under which all other data is collected.

\subsection{Data Users}

Potential users of AMPS data include researchers in a myriad of occupations, ranging from agencies of the U.S. government to private industry. The primary users of this data will be data researchers in the DOE community. Many will be both users of AMPS data and producers of AMPS data products. U.S. government agencies include the following:

- the Department of Energy

- the Department of Defense

- the Department of the Interior

- the Department of Agriculture

- the Department of State.

As stated in the introduction, private industry may also become a user of this data. Therefore, in the future, certain AMPS data products and data reduction techniques may be made available to private industry via technology transfer.

For example, combined data from the LANDSAT satellite system, the SPOT observation system, and the United States Geological Survey (USGS) system can reveal stressed vegetation in a geographic area. But that data will not show why the distress has occurred. When that data is combined with specific AMPS data, however, then the sources and effects of effluent releases can be compared and analyzed, and the effect of the releases on the surrounding environment can be determined, i.e., in this case, why the distress has occurred. 


\subsection{Data Management Process}

All AMPS participants will be part of the data management process. PNL is responsible for defining the procedures and infrastructure necessary for each organization to perform quality data management. Those procedures and that infrastructure comprise the AMPS Data Management Plan. Each organization will carry out its data management responsibilities for its aspect of the AMPS program, using the guidance provided by that plan. Each will prepare implementation-specific plans for each mission using the AMPS plan for guidance.

Data management for AMPS must take place at four levels:

- Pod Level - Data must be managed on the pod level, i.e., between sensors. It may be possible to use one sensor to "cue" the actions of another. It may also be possible to combine the data collected from multiple sensors to gain a better perspective about the target.

- Mission Level - Data must be managed on a mission level, i.e., between pods. As an example, the Synthetic Aperture Radar (SAR) pod can distinguish human artifacts from natural objects with great success. It can only determine the use of the object, however, if the object has a set of unique characteristics. The SAR data may be combined with data from other pods to better determine the use of an observed object. For instance, the combination of SAR data with thermal data from the multisensor imaging (MSI) pod would allow an interpreter to determine which objects were in use when the images were made.

- Analysis Level - Data must also be managed at the analysis level, i.e., at the AMPS system level. Data from the AMPS system may be combined with data from other systems used to collect or interpret data relevant to the same or like subjects. For example, AMPS data could be combined with data from the LANDSAT satellite system, the SPOT observation system, or maps from the USGS service.

\subsection{Major Data Management Elements}

Data management requirements are relevant to many elements of the data being considered and to data handling within AMPS. These elements include the following. A complete description of each will be provided in future documents:

- user data requirements

- data formats from individual AMPS sensor instruments

- metadata from individual instruments, such as instrument calibration and configuration 
- administrative data, such as flight information and pod configuration (collective instrument data)

- post-flight data and collected metadata

- implemented data format standards

- storage considerations for raw data and metadata

- production considerations for processed data

- data access, use, and distribution (means as well as form).

\subsection{POD Data Management Plan}

Data management for the pod instrument systems is critical. The pod data collection systems are a vital link in providing the data for research. Using the general templates provided by the AMPS Data Management Plan, shown in Figure 1.1, detailed Pod Data Management Plans (one for each pod) are used in the mission planning process to generate a Mission Data Management Plan. Each Pod Data Management Plan will be patterned after the templates that contain the following information:

- method of acquiring data to be used

- method of storing data aboard the aircraft

- method of transferring data from the aircraft storage media to the intermediate storage media (if any) and in what form

- method of transferring data to the laboratory computer to be used

- kinds of data quality analysés to be performed

- kinds of post-processing to be performed

- kinds of data products to be produced

- methods of packaging and distributing data products to be used.

These plans are prepared before each mission and convey implementation-specific requirements for both the pods and mission. By using these plans, it will be possible to determine the types of data to be collected before a mission. 
Each Pod Data Management Plan will describe for each instrument within a pod the flow of data from acquisition to final data product(s). Data may be transferred to different media between the time they are acquired and the final data product. Also, data may be manipulated, have quality information integrated, and have other value added.

The typical mission planning process will require a mission request, which will include objectives and data requirements and the Instrument Characteristics Document ${ }^{(a)}$ or instrument "spec sheet".

The mission will be planned according to the stated objectives and client requirements, defined within the stated capabilities of the instruments to be used. If conflicts arise between the requirements and the instrument capabilities, a dialogue between the mission planning team and the requester will be opened to resolve the conflict. The conclusion of the mission planning process will be a requester approved "Mission Plan".

The data management plan will also convey the process necessary to establish the data quality designation, which will accompany the data with its distribution. The key element of this aspect of data management is to clearly characterize the data so that researchers will be able to make optimal use of the data.

\subsection{Data Collection Instruments}

At present, three instrument carrying pods have been specified for use in the AMPS program. Responsibility for developing the pods has been assigned as follows:

- SNL Synthetic Aperture Radar (SAR) Pod - Pod 1

- RSL Multisensor Imaging (MSI) Pod - Pod 2

- LLNL Effluent Species Identification (ESI) Pod - Pod 3

Responsibility for developing pod instruments has been assigned as follows:

- LLNL Echelle Grating Spectrometer (EGS) for the ESI Pod

- PNL AMPS Data Management

- PNL Radionuclide Sampler for the ESI Pod

(a) The Instrument Characteristics Document is a compilation of measured instrument performance and capabilities obtained during shakedown flights. 
- PNL Air Concentrator/Ion Trap Mass Spectrometer (AC/ITMS) for the ESI Pod

- SRTC Atmospheric Krypton (Kr-85) Plume Grab Sampler for the ESI Pod.

Each pod and its instruments is described in the following. Briefly, though, Pod 1 (the SAR pod) deploys a synthetic aperture radar. It is particularly useful for imaging targets during all weather conditions, both day and night. Pod 2 contains size imaging instruments and cameras useful for remote target detection and material identification. Pod 3, the effluent species identification pod, has instruments for acquiring air samples, detecting radionuclides, and performing spectroscopy.

Targets for AMPS missions will all possess physical properties that the system's instruments can observe. Some of these properties are as follows:

- size, geometry, construction materials

- movement

- heat

- light (reflected or emitted)

- noise (some form of physical vibration)

- defined chemical properties

- radioactivity.

\subsubsection{Characterization of AMPS Instruments}

PNL has begun characterizing the various instruments used to collect data with the AMPS. A characterization of the instruments supplied by developers and pod integrators is included in the appendix. The pods and the instruments they are to contain are briefly described in the following paragraphs.

\subsubsection{Synthetic Aperture Radar Pod (Pod 1)}

Pod 1 contains the SAR, which acquires data onto an AMPEX digital tape unit. Data recorded on AMPEX DCRSi tapes consist of phase histories, image data, and positional data from an embedded Global Positioning System/Inertial Navigation System (GPS/INS) system. The phase histories are the raw radar echoes, whereas the imagery data consists of magnitude and phase data. On the ground, magnitude and phase imagery will be downloaded to 8-mm Exabyte tapes and/or CD-ROM. 


\subsubsection{Multisensor Imaging Pod (Pod 2)}

Each instrument in Pod 2 is controlled by a switch panel located in the aircraft and operated by a mission specialist. Time and position data are provided by the dual Garmin GPS-100 units on board the aircraft and recorded on tape within the pod. GPS time is manually set on a Society of Motion Picture and Television Engineers (SMPTE) time code generator. From the generator, time is set from a keyboard into the Daedalus/Compact Airborne Spectrographic Imager (CASI) and by switch into the video systems. The following instruments are contained in Pod 2.

2.5.1.2.1 Wild Heerbrugg RC-30 Large Format Camera. The RC-30 uses film widths of $9.5 \mathrm{in}$. with lengths of $400 \mathrm{ft}$. A useful image area of $9 \times 9$ in. per frame results in 420 high-resolution photographs per roll. Photography can be acquired at three-second intervals during flight, permitting overlapping photographic coverage of the ground with aircraft speeds of 250 knots or slower at altitudes of $1,000 \mathrm{ft}$ and above.

2.5.1.2.2 Barr and Stroud IR-18 Thermal Imager. Data acquired with the IR-18 is recorded with a TEAC V-80AB-F. The high-resolution video recorder utilizes a Hi-8-mm format, which captures higher frequencies and bandwidths than conventional VHS video recorders.

2.5.1.2.3 CASI Hyperspectral Imager. The imager can be operated in an imaging or spectrometer mode. In the spectrometer mode, 288 spectra can be recorded for a small subset of scene elements. In the imaging mode, complete spatial coverage is obtained for user-selected sets of spectral bands.

2.5.1.2.4 Intensified Monochrome Charge Coupled Device (CCD) Camera. This highresolution CCD camera is a highly sensitive COHU 5560 camera designed for low light level conditions. The images formed by this camera are recorded on another TEAC V-80AB-F high-resolution video recorder.

2.5.1.2.5 Sony DXC-750 3-CCD Video Camera. This video camera uses three high-resolution CCDs. Each recorded frame consists of 380,000 pixels. Image data are recorded on a Sony DVR-2 Portable Digital Cassette Video Tele-Recorder (VTR).

2.5.1.2.6 Airborne Multispectral Scanner. The Daedalus 3600 Airborne Multispectral Scanner (AMS) system is a dual optical port multispectral scanner that simultaneously records up to six spectral channels directly onto 8-mm digital tape. A total of 10 spectral bands are available; up to six may be selected for recording by the operator.

\subsubsection{Effluent Species Identification Pod (Pod 3)}

The purpose of this pod is to field sensors that are capable of identifying the chemical species in airborne effluents. The initial sensor complement includes one stand-off optical sensor and three air 
samplers/analyzers. Sensor operation will be controlled through a single wire ethernet control network. Position and time data will be provided to the sensors from a GPS receiver in the fuselage of the aircraft. Included in this pod are the following instruments.

2.5.1.3.1 Target Locating and Tracking Platform. A 14-in. Versatron ball turret is externally mounted and equipped with a video camera and a Mitsubishi 3-5 $\mu \mathrm{m}$ imager. A Westinghouse 8-12 $\mu \mathrm{m}$ MicroFLIR (Forward Looking Infrared) can be accommodated in the turret. An autotracking system will be integrated into Pod 3.

2.5.1.3.2 Echelle Grating Spectrometer. The EGS collects the infrared spectrum of a point source by two-dimensionally dispersing the spectrum onto a $256 \times 256$ (InSb) infrared detector array. The analog signal intensity from each detector element is digitized by a 12-bit analog-to-digital converter (ADC) and is stored on a ruggedized solid-state disk.

2.5.1.3.3 Air Concentrator/Mass Spectrometer. Direct inlet sampling of the air stream permits real-time measurement of a broad range of chemical species below the part-per-billion (ppb) concentrations. Additionally, a sorbent-based concentration system is used to boost detection sensitivity for airborne organic compounds to sub-ppt (parts-per-trillion) concentrations. The discrete sampling throughput of the mass spectrometer system with the air concentrator is reduced to one sample every 30 seconds to 2 minutes, depending on the required concentration factor.

2.5.1.3.4 Airborne Radionuclide Detector. Whole air is sampled at a rate of $10 \mathrm{~m}^{3} / \mathrm{min}$ through a filter cartridge placed in front of a high-sensitivity, large-volume intrinsic germanium (IGe) detector. The purpose is to provide near real-time analysis of gamma-emitting radionuclides in the sampled air stream as they are being collected on a filter cartridge. Initially, the system will have a capacity of 1020 -filter cartridges. The in-stream sampling time between cartridge exchanges can range from as short as 10 seconds to as long as several minutes.

2.5.1.3.5 Krypton Sampler. The Aerial Krypton Grab Sampler is a whole-air sampler that selectively concentrates the noble gas fraction from the air stream for subsequent analysis of the $85 \mathrm{Kr}$ concentration at a ground-based laboratory. It samples and processes air at the rate of $10 \mathrm{~L} / \mathrm{min}$ (i.e., 10 minutes to collect and process $100 \mathrm{~L}$ of air) and is capable of collecting up to 12 discrete air samples. Post-mission laboratory analysis of the collected $\mathrm{Kr}-85$ samples can be performed by radioactive decay counting or through mass spectrometric (MS) methods.

\subsubsection{Aircraft Instrumentation}

The RP-3A aircraft provides the instrument data sources described in the following paragraphs.

2.5.1.4.1 Outside Air Temperature System. There are no facilities at present to record this information. 
2.5.1.4.2 Garmin GPS 100. Each pod will have its own GPS; however, this information is available to and may be recorded by the pods.

2.5.1.4.3 Litton Inertial Navigation System. There are no facilities at present to record navigation data. The capture of data provided by the Inertial Navigation System (INS) is important for proper image rectification. However, Pod 2 will have its own INS for rectifying and registering collected images.

\subsubsection{Instrument Developers and Pod Integrators}

Instrument developers will be primarily concerned with the data that the developed instrument was designed to collect. Improvements in the performance of these sensor systems will greatly depend on the ability of the developers of these instruments to analyze, interpret, and store the collected data. As instrument developers gain experience in the analysis, interpretation, and internal storage, or forwarding, of the collected data, improvements in the next generation of instruments employed within the AMPS system will follow.

The combination of sensor systems within the pod is another consideration. Construction of the pod, and the physical properties (air drag, optimal use of space, heat generated in flight, etc.) of the pod are other considerations to be dealt with. As the AMPS system becomes operational, the combination of the various data acquisition and dissemination systems will have to be analyzed to obtain optimum performance.

\subsubsection{AMPS Instrument Systems Constraints}

The following list defines the constraints that pertain to the AMPS pod instrument systems:

- All pods within the AMPS system are self contained. That is, all data are collected, processed, and stored for later retrieval within the pod. No additional systems are required external, or. complementary, to the pod for AMPS operations to occur, other than manually kept flight logs and data entered at the operator stations.

- The transfer of data, in real time, outside the AMPS pod is not required.

- A generic as well as integrated data collection system for AMPS pods is not planned and will not be created. This means that all instrument systems will use individual data collection algorithms and mechanisms, provided by instrument developers and pod integrators. 


\subsection{Requirements}

A detailed and comprehensive set of requirements is needed to design and build a hardware/ software system such as AMPS. The users' expectations must be set forth in the requirements, and the system is designed after a thorough analysis of the specified requirements. The completed system will be measured against the requirements specifications.

This set of AMPS requirements center around the data management infrastructure--from mission planning to data acquisition to data storage to data dissemination. They include data format standards, data quality assessment, and metadata. The following provides an overview of the areas that the requirements must address.

\subsection{Data Management Infrastructure}

The AMPS data management requirements are to provide the infrastructure through procedures and plans for guiding AMPS contributors in the design of data acquisition and sensor systems as they relate to the data associated with them. The plan only applies to data intended for distribution as part of the AMPS program.

\subsubsection{Mission Planning}

Key to the data management planning process is addressing data requirements before missions are conducted so the design of the data to be acquired will meet the needs of the user community. The AMPS Data Management Plan facilitates this process through the pod and mission templates. The pod providers and the mission planners will address the data specifically through the templates during the mission planning process. The AMPS data management plan will provide complete data planning development before AMPS data acquisition.

\subsubsection{AMPS Data Acquisition}

The AMPS data management plan provides for data management criteria related to the data acquisition process for all AMPS instruments described in Section 2.5, Data Collection Instruments. The purpose of the criteria is to ensure that the acquisition process provides data and supporting metadata that meet the user communities' needs. Builders of the data acquisition capability will apply the criteria to their designs.

\subsubsection{Metadata}

In addition to the data collected by instruments on targets, metadata (or data about data) will be collected. Sets of data will be collected that relate to the pod in which the instruments are located, the operating environment of the instruments, and the ambient conditions of the flight. In addition, there 
will be sets of more static data that describe such things as the instruments themselves, calibration values, flight parameters, and mission goals. All are important to understanding the context of the actual instrument readings.

To fully understand all this metadata, it is necessary to be able to describe and identify all of these various data elements. This type of information on the AMPS program will be collected and maintained in a database called a "data dictionary."

For example, an anemometer that periodically records wind velocity would produce a data set that contains values for Time-of-Day, Wind-Speed, and Wind-Direction. That data collected by the instrument might appear in the data dictionary in the following format:

$\bullet \bullet \bullet$ | year-month-day:hour-minute-second | Wind-Speed | Wind-Direction | . .

or

$\bullet \bullet \bullet|1999-06-21: 12-31-55| 012.50|137.33| \ldots$

The metadata about this format would be shown as follows:

$\begin{array}{lll}\text { Time-of-day } & \text { Type: } & \text { Compound } \\ & \text { Size: } & 6 \text { Simple elements } \\ & \text { Purpose: } & \text { Unique identification of instrument reading } \\ & \text { Source: } & \text { System clock } \\ \text { Year } & \text { Type: } & \text { Integer } \\ & \text { Size: } & 4 \text { digits } \\ & \text { Value: } & >1993 \\ & \text { Purpose: } & \text { Attribute of Time-of-Day } \\ \text { Month } & \text { Type: } & \text { Integer } \\ & \text { Size: } & 2 \text { digits } \\ & \text { Value: } & 0<>13 \\ & \text { Purpose: } & \text { Attribute of Time-of-Day } \\ & & \\ \text { - } & & \\ \text { Wind-Speed } & \text { Type: } & \text { Decimal } \\ & \text { Format: } & 999.99 \\ & \text { Units: } & \text { meters per second } \\ & \text { Purpose: } & \text { Attribute of Wind Velocity } \\ & \text { Type: } & \text { Decimal } \\ \text { Wind-Direction } & \text { Format: } & 999.99 \\ & \text { Units: } & \text { Degrees from True North } \\ & \text { Purpose: } & \text { Attribute of Wind Velocity }\end{array}$


In addition to describing the data elements, the data dictionary requires that each element has a unique name. This will ensure that all data elements called, for example Wind-Speed, represent the same thing, regardless of the data sets in which they appear. All users would be confident that any discussion or use of Wind-Speed would refer to the same thing.

The same type of data dictionary entries would appear about other, more indirect data elements. For instance, a data producer may assign a quality flag to a data set, or even to the individual elements within the set, to give a data user some idea about how "good" the values for a particular set of instrument data might be. In this case, data are being added through a medium other than the instrument itself, but such data are still an integral part of the data set.

In this case, the data dictionary would have to be modified to include the element definition:

$\begin{array}{lll}\text { Quality-Flag } & \text { Type: } & \text { Integer } \\ & \text { Size: } & 1 \text { digit } \\ & \text { Values: } & 0 \text { means no quality assignment } \\ & 1 \text { means very poor quality } \\ & 2 \text { means poor quality, etc. } \\ & \text { Source: } & \text { Data Producer } \\ \text { Purpose: } & \text { To provide a subjective evaluation of the data } \\ & \text { quality }\end{array}$

While this discussion has primarily dealt with instrument recorded data sets, the same is true of the other types of data sets; e.g., flight logs, instrument specifications, flight parameters, mission plans, and ambient environmental conditions.

By its very nature, metadata are static in the sense that they do not change. When changes to metadata do take place, they are usually associated with a significant restructuring of the data gathering or utilization functions (such as new instruments or data production methods). Metadata, however, do provide the necessary level of consistency that will allow merging many seemingly disparate data sets into new contexts and associations.

\subsubsection{Long-Term Data Storage}

The Data Management Plan will address the policy and procedures for archiving data. In general, those organizations responsible for an instrument will maintain the archives of data and corresponding metadata associated with the instrument, according to the established policies and procedures. Responsibilities for the archives are described in the following. 


\subsubsection{Synthetic Aperture Radar Pod (SAR) (Pod 1)}

The original AMPEX DCRSi tapes and one copy of the data copied to 8-mm tape and/or CD-ROM will be stored at SNL.

\subsubsection{Multisensor Imaging Pod (MSI) (Pod 2)}

The original video tape cassettes and photographic negatives will be archived at RSL in their Archive for Aerial Film. Selected/required photographs may be digitized by RSL personnel.

\subsubsection{Effluent Species Identification Pod (ESI) (Pod 3)}

Data from Pod 3 will be stored in the following ways:

- Target Locating and Tracking Platform - All recordings will be stored at LLNL.

- Echelle Grating Spectrometer (EGS) - Data will be archived at LLNL.

- Air Concentrator/Ion Trap Mass Spectrometer (AC/ITMS) and Airborne Radionuclide Detector - Data will be archived at SRTC.

- Aircraft Data - Data archival has not been addressed at this point, because the data recording method has not yet been decided.

\subsubsection{Access}

AMPS data are stored at the laboratories responsible for the pod from which any particular data are acquired. Requests for particular data sets must be made to the laboratory at which it resides. PNL will facilitate data access by generating a "data catalog" that will be updated after each AMPS mission. The data catalog will contain references to all AMPS data that has been acquired and will include instruments used, geographic location, date and time, data repository, etc.

\subsubsection{AMPS Data Quality}

The AMPS program will collect data for use by data researchers who are not directly associated with AMPS. Information on the quality of the data collected is one type of information that users of AMPS data will require. The standards for the quality of the data collected, however, will be established by the researchers. They will specify quality requirements in the Data Management Plan prepared for each mission. Information on the quality of the data collected will also useful to AMPS investigators in diagnosing instrument performance.

Users of AMPS data will need to choose which data to analyze. In making this decision, they will be interested in knowing which data are "good", i.e., whether the instrument is believed to have been 
operating correctly; which data are "suspect", i.e., whether the instrument may have had a problem or whether other factors may have affected the data; and which data are "bad", i.e., whether the instrument was known to have problems. If possible, more quantitative indicators of data quality are desirable. Procedures and guidance for determining data quality are expected to be part of the approved data management plan.

\subsubsection{Management}

PNL has been assigned responsibility for defining data management procedures for the AMPS program. As such, PNL is currently assessing the requirements for the following:

- managing sensor data from the AMPS instruments

- acquiring and managing accompanying metadata

- assessing the quality of AMPS data.

PNL will develop specific AMPS program data management procedures based on the results of this requirements assessment. As a precursor to this analysis, it has been determined that four areas of consideration have to be addressed in order to complete the assessment, as described above, nominally. These areas are as follows:

- time synchronization

- position determination

- the pointing of the sensor at the time of sighting

- the logging of information as it is received.

These areas will be discussed individually in the following.

\subsubsection{Time Synchronization}

Time synchronization is required for concurrent observations of the same entity by different observers/sensors. Concurrent observations can be used both to validate sensors and for the synergistic use of multiple data sets. Because a generic as well as integrated data collection system for AMPS pods is not planned and will not be created, it is imperative that time and position information be captured and recorded as the observations occur. Because it is also an assumption that the transfer of data, in real time, outside of the AMPS pod is not required, post-flight analysis of the data (i.e., after it is collected from the pod), can combine the observations. This combination will then present a comprehensive image of the target that was being observed. 


\subsubsection{Position Determination}

The requirement to accurately determine the positions of targets at the time of the observation is governed by the need to reference the entity for later data acquisition efforts or for some form of progressive action. It should also be noted that all position observation systems really form position estimates, which contain some form of residual error. There are methods to quantify and to minimize this error; however, it is never truly totally removed. Position error tolerances for AMPS user systems will have to be determined.

\subsubsection{Field of View of the Sensor}

An important part of each flight will be to establish sampling backgrounds, both natural and artificial. Those factors that will affect the field of view of the sensor, and hence the validity of the gathered data, are as follows:

- target objective, location, and attitude

- flight altitude

- angles of approach to the target objective during ingress and egress, preferred and actual

- desired and actual time on station

- angle of bank - pitch, roll, or yaw

- aircraft speed over the target area

- controlled variables (search patterns, multiple patterns, operator discretion)

- relevant flight profile characteristics overlap

- field of view restrictions on the subject sensor (internal and external).

\subsubsection{Information Logging}

The ability of an instrument system to collect, process and store information into a retrievable information log is vital to the success of the AMPS effort. All data analysis and fusion depends on this ability. Because the assumption that all pods within the AMPS system are self contained remains valid, the ability to establish an information log is incumbent on the individual instrument developer. Management of the information contained in these logs is heavily dependent on the form of the information as stored and on the elements of data management as cited above. The final plan will specify information logging requirements. 


\subsubsection{Performance}

All systems within the AMPS program need to be analyzed for optimum performance. These include the individual instruments, the pods, the aircraft, and the overall data flow from the instrument to the user community.

\subsubsection{Standards}

Standards provide the framework for a diverse group of individuals belonging to different organizations to work together nearly autonomously to achieve a mission. In the case of AMPS, the Data Management Plan will provide standards and guidance for information exchange standards. Standards established in the AMPS Data Management Plan will augment existing applicable government standards and consider draft standards currently under development. Other standards, such as for software, will be at the discretion of the controlling organization.

The Data Management Plan will address, at a minimum, the core standard areas described in the following paragraphs.

\subsubsection{Data Format}

The multitude of sensors associated with AMPS provide data in a range of formats and media. The Data Management Plan will address standard formats and media to simplify the process for distributing the data and subsequently optimize the data distribution effort. Data format standards will also reduce the effort and tools necessary for data users to import the data into their analysis systems.

\subsubsection{Data Dictionary}

Standardized data formats do not ensure that codes for data within the format are unique. Therefore, the data dictionary provides a rigorous definition for all data and the attributes that describe them. The data dictionary eliminates duplication and contradiction in data attributes commonly found in data sets whose origins are from diverse sources.

\subsubsection{Information Catalog}

Because the providers of AMPS data will be archiving the data, users will need access to the location of the various data sets as well as information on the data content. The Data Management Plan will provide the framework for data providers to make available catalog information so users can readily and easily determine the location and availability of information. 


\subsubsection{Quality Assurance}

The Data Management Plan will describe the process standards for data quality assurance with the goal of enabling data providers to convey clearly (i.e., define) what the corresponding data quality is to users.

\subsubsection{Configuration Management}

One element of data management is configuration management. The Data Management Plan will convey the configuration management for all AMPS data. Each data provider, before a mission, will prepare a Mission Data Management Plan using the AMPS Data Management Plan Mission Template to fulfill configuration management requirements for data. The AMPS Data Management Plan provides data configuration information before and beyond missions. Thus, the Data Management Plan will provide all guidance specific to data configuration management.

\subsection{Data Interchange Architecture}

The AMPS data interchange architecture seeks to base itself on accepted national and international standards. For the purpose of AMPS, the most important is a standard file structure. The following is background on these standards and how they apply to AMPS.

\subsubsection{Software Standards}

The relationship of the various software standards organizations is complex and dynamic. Yet, many well known computer languages, systems, libraries, and applications have been formalized in one or more standards. For example, the UNIX system is specified by FIPS 151-1, POSIX.1, POSIX.2, and others. The popular database query language SQL is standardized in FIPS 127, and equivalent ANSI and ISO documents. The well known graphics standard, CGM, is formalized in standard ANSI X3.122-198X, and also in MIL-D-28003.

User organizations such as UniForum and UNIX International have been established to help users of computer resources understand and acquire electronic information processing standards. The various organizations are loosely related to each other and each uses a different numbering and identification scheme. The user groups can help potential standards users sort this out.

Frequently, methods of computerized information interchange become so well known and widely used that they become known as de facto standards, i.e., a standard in fact. Some de facto standards eventually become formalized by national and international organizations. The ASCII characters may be the best known example of a de facto standard turned formal. 
Though the standard efforts described in this report seem to specify UNIX-based tools, most are independent of operating environment, and many include counterparts in environments outside UNIX, such as OS/2, MS-DOS, NT, VMS and Macintosh OS.

Virtually any library application program interface (API), interface, or application needing to be implemented on multiple platforms is a candidate for software standardization.

In addition to software standards for operating systems, etc., ANSI/IEEE has produced a series of standards for software engineering, project management, software documentation, and quality assurance.

\subsubsection{National Standards}

Standards for data processing exist in several forms and have been published by several national organizations, agencies, and associations. Among these are standards of the following titles:

- ANSI - American National Standards Institute

- IEEE - Institute of Electrical and Electronic Engineers

- NIST - National Institute of Standards and Technology

- FIPS - Federal Information Processing Standards

- GOSIP - Government Open Systems Interconnection Profile

- OSI - Open Systems Interconnection

- MIL - U.S. Military Standards.

\subsubsection{International Standards}

In addition to United States national standards, there are international standards organizations. These include the following:

- ISO - International Standards Organization

- ECMA - European Computer Manufacturers Association

- MITI - Ministry of International Trade and Industry

- X3 - Accredited Standards Committee for Information Processing. 


\subsubsection{Standards User Groups}

Many user groups have involved themselves in the business of promoting software standards and distributing information on standards. Distributing information on software standards is one of the biggest endeavors of the 1990s. User groups include the following:

- UniForum - formerly /usr/group

- UI - UNIX International

- X/Open - User, vendor group for promoting standards.

\subsubsection{Open Standards}

Generally, open standards are standards that specify interfaces used or presented by open systems, but do not include the implementation. Open standards usually are made available to the public through public domain releases or nonproprietary licensing. Because only the interfaces are specified in open standards, different vendors can use different technologies in their implementations. Thus, vendors compete based on performance rather than on the merits of the user's interface with the software.

Numerous consortiums have been established for the purpose of building and defining open standards. Some are very well known in the community of users; others are not. For example, the following consortiums promote and develop open standards:

- POSIX - Portable Operating System Interfaces, IEEE

- OSF - Open Software Foundation

- COSE - Common Open Software Endorsement

- CORBA - Common Object Request Broker Architecture.

\subsubsection{De Facto Standards}

Another kind of software standard worth considering in some software projects are de facto standards, sort of pseudo standards, which come about as the result of widely used public domain software packages. Some have become de facto standards, not because of the documentation that goes with them or ballot of an agency's membership, but because of their wide application and acceptance among software users of multiple industries.

Examples of such software are RCS, GNU Make, netCDF, and PERL. All these packages have many users. Each is supported through a formal association or agency. Each has been in use long 
enough that they are now considered stable for the current state of the art. Their users have set up teleconferencing style interest groups for helping others with problems, sharing of information, and as a kind of informal support mechanism. Documentation and operating manuals are kept up to date. Many are available for use on different kinds of platforms, e.g., UNIX, VAX/VMS, and MS-DOS.

Not all public domain software packages are worth consideration in programs such as AMPS, as not all are as well maintained and as universal as the four examples above. A careful study of any software, and its support history, should be performed before concluding its applicability to the AMPS program.

\subsubsection{Data Management Standards Criteria}

Standard methods and policies for storing and distributing AMPS data should be adhered to, to promote ease of access by the AMPS data user community. Components of storage and distribution are file systems, archives, and distribution methods.

\subsubsection{File Systems}

In order that data collected under the AMPS project be available for the widest possible community of users and on different platforms, file systems used to store processed data from AMPS missions should conform to well-known file system standards, e.g., NFS and AFS.

Data sets collected in AMPS can be large, and thus file systems of AMPS data hosts must be capable of storing multiples of gigabyte collections of files.

Within a site's local network, it should be possible to cross mount partitions on the AMPS data hosts to both UNIX and PC platforms. It is not necessary to cross mount site-to-site.

A standard directory structure for data stored at AMPS data hosts shall be established. The (sub)directory naming convention will be made general enough to meet the needs of any data site. Any anomalies to standard names will be accommodated through symbolic directory links.

Path names will be relative to an unnamed root (sub)directory. In this way, entire missions or sets of missions can be moved from site-to-site or copied to another file system without the need for file systems on different data hosts to have the exact same directory setup.

Path names and (sub)directory names shall be chosen and limited to accommodate all file systems adopted for use in AMPS, e.g, UNIX or PC, plus all possible storage and distribution media, i.e., on-line disk files and CD-ROM. 


\subsubsection{Data Archiving}

Data sets should be archived on off-line media, i.e., high-density tape or optical media, at regular intervals. Efficient data compression standards for image data exist and will be studied and recommended.

Archived data set media will remain at the site of the data host. Each site will be responsible for maintaining its own physical archival system and for establishing archival methods. Each AMPS site may choose to utilize its own system administration staff to accomplish archiving and backup, using procedures already proven and working. Archival media should be of a reliable industry standard but need not be uniform at every AMPS site.

Once a data set has been archived, it may (or may not) be deleted from on-line storage. The on-line/archived status should be a switch in the on-line catalog for the data set in question. Catalog entries for archived data sets should remain on-line.

A procedure for calling up archived data sets should be defined. This procedure should be uniform across all AMPS data sites, but the implementation at each site might be different. Data sets, thus restored, can be placed back on-line or written to off-line media, e.g., CD-ROM, for distribution to users.

\subsubsection{On-Line Distribution}

Data sites who elect to make files managed at that site available on-line to the AMPS community shall utilize a standard on-line file access and/or transfer method to be determined.

One possible choice for on-line access is the File Transfer Protocol (FTP) of the Internet, the world's largest and best known computer network. An advantage to this method is the wide knowledge of FTP among potential users. A disadvantage is if any AMPS user site(s) only has electronic mail network access.

Another possibility for file access is electronic mail. This method would be an advantage to any user sites only having e-mail access to computer networks. Several of the standards agencies deal with standards for electronic mail, e.g., X.400, which is based on level 4 of the OSI 7 layer protocol standards.

Finally, it is possible for a data host to offer both file transfer and electronic mail services.

\subsubsection{Off-Line Distribution}

Data sites may elect to make files managed at that site available off-line via high density media. Methods and standards for formatting distributions on high-density tape and on CD-ROM will be selected. 
Data sites offering off-line distribution should make U.S. Post, electronic mail, and FAX available as ordering methods.

\subsubsection{Data Catalog}

An on-line catalog for AMPS data is anticipated. The goal here is to make each participating host data site responsible for maintaining its piece of the data catalog and to ensure that the master records of the data catalog can be located on their storage.

The catalog sections set up at each participating data site would then become a part of the overall catalog. Thus, catalog users would actually access a distributed database of catalog entries.

Possible tools to accomplish a distributed catalog on a network are the GOPHER and WAIS programs. Both physical and security issues associated with using and setting up software tools for distributed catalogs will be studied and recommended.

\subsubsection{Information Services}

Distribution of information relating to available data at host sites can be accomplished through the U.S. Post, FAX, electronic mail, or a computer bulletin board (BBS) such as USENET.

If the BBS approach is included, then procedures and protocol for using it need to be adopted. The protocol should be documented in a FAQ (frequently asked/answered questions) document available via electronic mail or FTP from the maintainer's host.

\subsubsection{Data File Standards Criteria}

Standards for data file storage and format will be evaluated. Criteria for evaluation will include, but not be limited to, the elements listed in this section.

Though there may be differences in the data collected by the instruments in the three pods, a goal of this task is to eventually achieve a uniform file wrapper that all data sites can utilize.

\subsubsection{Raw Data}

Each instrument collects certain elements of raw data. It should be possible to recreate the data formats exactly from processed data files. To accomplish this goal, the processed data file cannot contain any floating point data that was derived from integer data. Rather, integer data plus scale factors should be stored to achieve both the ability to extract scaled floating point data or the original raw data.

Whenever possible, raw floating point data should utilize well-known standards, e.g., IEEE-754. 


\subsubsection{Image Processing and Graphics}

The file format standard adopted by this data management plan must be able to store and use image data. The term "image data" means pixel data (monochrome or 3-color) arranged in a 2-d rectangle as a digitized picture. Dimensions of the picture and attributes of pixels must be accommodated in the file.

The file format must also support data of graphical orientation, especially data produced by or compatible with geographic information systems (GIS). This requirement is mainly for off-line integration of AMPS data with other (sub)systems.

\subsubsection{Attributes and Metadata}

The file format standard adopted by this data management plan must be able to store and use metadata, i.e., pseudo-data which describes the data by its attributes.

Metadata can also be used to describe the nature, structure or layout of the file itself.

\subsubsection{Instrument Differences}

Though the goal of this plan is to accomplish a uniform data wrapping method, differences between the instruments of the various pods must be accommodated.

\subsubsection{Self-Describing Data File}

Merits of self-describing data files shall be evaluated for application to AMPS. Some examples are TIFF, CDF, netCDF, and HDF as well as several FIPS publications.

\subsubsection{Selection Process}

File standards selection shall be driven by a process of finding potential candidates, evaluating them, comparing attributes of each possible solution with the needs of AMPS, and demonstrating selected candidates when possible. This process will be followed by documentation, adoption and subsequent approval of policy.

A similar multi-step process will be used to specify AMPS data management and information service procedures.

\subsubsection{Investigation}

The investigative process will include a literature search for formal standards dealing with data format, image processing, GIS, graphics, and self-describing data. 
Open software and publicly available tools and resources will also be searched via tools of the Internet, e.g., ARCHIE, VERONICA, and GOPHER, and documentation available from ES-Net.

\subsubsection{Evaluation}

After performing a reasonable search, PNL will evaluate each data standard to develop a list of potential standards candidates for AMPS. Results of this search will be presented in a memo to participating AMPS team members.

\subsubsection{Needs of AMPS}

A standard information architecture will be proposed via the investigation and evaluation mentioned in Section 3.2.4.2, Evaluation, of available standards through a dialog between AMPS data researchers, pod integrators, and PNL.

PNL anticipates that no one data standard will be universally accepted by the AMPS community and that some compromise and merging of ideas will be necessary to successfully integrate and facilitate AMPS data interchange.

\subsubsection{Demonstration}

Whenever possible, active demonstrations of potential standards candidates will be set up using systems at PNL and participating AMPS sites. This practice should be especially useful in getting to an acceptable and working data catalog design.

\subsubsection{Documentation}

All procedures, protocols, and decisions of the AMPS data management plan implementation will be documented and made available, both off-line and on-line.

FIPS and ANSI standards for software documentation will be evaluated for applicability to the AMPS data management plan implementation.

On-line documentation shall include both ASCII and postscript files. On-line access will be compatible with methods chosen for on-line data distribution; see Section 3.2.2.3.

The formal AMPS data management plan implementation shall be addressed in the FAQ.

Documentation off-line availability shall be via U.S. post, FAX or CD-ROM. 


\subsubsection{Adoption}

All facts considered, PNL's recommendations will be forwarded to AMPS program management for their review and approval.

PNL will create and document an implementation plan to bring about a smooth transition to the approved AMPS data interchange architecture and standards. 
Appendix A

AMPS Instrument Data Characteristics 


\subsection{SAR Pod (Pod 1)}

\subsection{Synthetic Aperture Radar (SAR)}

\begin{tabular}{|c|c|}
\hline \multicolumn{2}{|r|}{ Instrument Description } \\
\hline Instrument Name & Synthetic Aperture Radar \\
\hline Manufacturer & Sandia National Laboratories \\
\hline Serial Number & N/A \\
\hline Hardware Version & N/A \\
\hline $\begin{array}{l}\text { Operational Ranges } \\
\text { (Temp., Altitude, etc.) }\end{array}$ & $\begin{array}{l}\text { Temperature } \\
\text { Controlled in pod to be close to laboratory temperature range } \\
\text { Altitude } \\
\text { Depends on imaging geometry and desired swath width. } \\
\text { Roughly } 3-15,000 \mathrm{ft} \text { AGL. Max: } 25,000 \mathrm{ft} \text { MSL. } \\
\text { Slant Range } \\
\text { Depends on imaging geometry. } 4.3 \text { to } 7.8 \mathrm{~km} \text { nominal. }\end{array}$ \\
\hline $\begin{array}{l}\text { Performance Parameters } \\
\text { (i.e. range of acquisition freqs.) }\end{array}$ & $\begin{array}{l}\text { Center Frequency } \\
14.85 \mathrm{GHz} \text { nominal } \\
\text { Bandwidth } \\
1 \mathrm{~m} \text { resolution at } 180 \mathrm{MHz} \\
3 \mathrm{~m} \text { resolution at } 60 \mathrm{MHz}\end{array}$ \\
\hline Normal mode of operation & Side looking strip map \\
\hline Sampling frequency & $66 \mathrm{MHz}$ nominal, independent of resolution \\
\hline Calibration Procedure & $\begin{array}{l}\text { Calibrated for range and signal return against a predetermined } \\
\text { corner reflector field during initial checkout flights. After- } \\
\text { ward, system is self-calibrating. Calibration can be verified as } \\
\text { needed against corner reflectors when convenient. }\end{array}$ \\
\hline Error Detection/Correction & Skilled operators \\
\hline $\begin{array}{l}\text { Data Recording Capabilities } \\
\text { (how long, how much) }\end{array}$ & $\begin{array}{l}\text { Worst case example: } 45 \text { GBytes in } 1.2 \text { hours with phase } \\
\text { histories and } 3 \mathrm{~m} \text { data. }\end{array}$ \\
\hline
\end{tabular}


Radar phase histories and complex images are stored in flight on tape using an AMPEX DCRSi recorder system. The AMPEX tape cartridge is considered to be the archive media and as such will be maintained at SNL for future use. Since the AMPEX tapes are not considered to be a deliverable, the format of the data stored on those tapes is not included here.

Image data and associated metadata are downloaded post-flight to the delivery media, which is to be CD-ROM or 8-mm Exabyte tape, depending on the size of the data set. The data will be formatted as shown in the following tables.

SNL assumes that phase histories are not a deliverable item at present. A phase history data product, along with associated documentation on its use, could be developed if needed. It would be delivered on Exabyte tape. Image data are currently delivered in GFF format. This format is described in a separate document maintained by SNL.

\begin{tabular}{||l|l||}
\hline \multicolumn{2}{|c|}{ Data Record - Processed Form } \\
\hline Record Length & \\
\hline Names of data fields 1 Instrument Data - Processed Form for each named field) \\
\hline Record structure & Image Data - GFF Format at present \\
\hline Recording Media & \\
\hline
\end{tabular}

\begin{tabular}{||l|l|}
\hline \multicolumn{2}{|c|}{ Instrument Data - Processed Form } \\
\hline Name & Image Data - GFF Format at present \\
\hline Source (detector name) & SAR \\
\hline $\begin{array}{l}\text { How generated (conversion } \\
\text { process/algorithm }\end{array}$ & SAR \\
\hline Engineering Units & \\
\hline Normal Range & \\
\hline Uncertainty & \\
\hline $\begin{array}{l}\text { Structure (8-, 16-, 32-bit, signed) } \\
\text { (Precision for floating point) }\end{array}$ & \\
\hline $\begin{array}{l}\text { Data that may be correlated with this } \\
\text { data to assess quality }\end{array}$ & \\
\hline
\end{tabular}




\begin{tabular}{||l|l|}
\hline \multicolumn{2}{|c|}{ Data Description } \\
\hline Targeted User(s) & Unknown \\
\hline How will it be used & Unknown \\
\hline Useful life of the data & Computer tape shelf-life \\
\hline Aircraft Data Available/Required & Does not require data from aircraft \\
\hline Meteorological Data Required & $\begin{array}{l}\text { Winds at various altitudes. } \\
\text { General weather conditions }\end{array}$ \\
\hline Forms in which data may be requested & $\begin{array}{l}\text { Image data on 8-mm video tape (Exabyte) } \\
\text { Images in GFF format. }\end{array}$ \\
\hline $\begin{array}{l}\text { How data of interest may be identified } \\
\text { by users for extraction }\end{array}$ & \\
\hline
\end{tabular}




\subsection{Multisensor Imaging Pod (Pod 2)}

\subsection{Wild Heerbrugg RC-30 Large Format Camera}

The RC-30 accepts a 400 -foot roll of film allowing approximately 420 exposures. There is a manual clock inside the camera that must be set prior to each flight. A flight log is maintained by an on-board operator. Each frame is numbered in sequence with the time, date, and scale. The time interval between exposures is dependent upon the altitude. Overlapping of frames is adjustable. The lens is calibrated prior to the flight. After a flight, the film is processed, proofed, and cut. The photographs may be scanned into a GIS. The photographs are archived at RSL in their Archive for Aerial Film. They are currently attempting to interface the camera to GPS.

\begin{tabular}{|c|c|}
\hline \multicolumn{2}{|c|}{ Instrument Description } \\
\hline Instrument Name & Wild RC-30 \\
\hline Manufacturer & Leica \\
\hline \multicolumn{2}{|l|}{ Serial Number } \\
\hline \multicolumn{2}{|l|}{ Hardware Version } \\
\hline $\begin{array}{l}\text { Operational Ranges } \\
\text { Operating temperature } \\
\text { RC30 Camera System } \\
\text { Head of viewfinder/nav. sight } \\
\text { Maximum relative humidity } \\
\text { Maximum ambient vacuum }\end{array}$ & $\begin{array}{l}-40^{\circ} \mathrm{C} \text { to } 50^{\circ} \mathrm{C} \\
-30^{\circ} \mathrm{C} \text { to } 50^{\circ} \mathrm{C} \\
95 \% \\
\text { ICA0 standard atmospheric pressure, altitude } \\
50,000 \mathrm{ft}\end{array}$ \\
\hline \multicolumn{2}{|l|}{$\begin{array}{l}\text { Performance Parameters } \\
\text { (i.e. range of acquisition freqs.) }\end{array}$} \\
\hline $\begin{array}{l}\text { Modes of operation } \\
\text { SINGLE } \\
\text { SPIRAL } \\
\text { INTERVAL }\end{array}$ & $\begin{array}{l}\text { Single exposure, without FMC } \\
\text { Serial exposures, controlled by } \\
\text { moving spiral, with FMC external } \\
\text { exposure release } \\
\text { Single exposure, with FMC } \\
\text { Serial exposures, controlled by } \\
\text { intervalometer, with FMC }\end{array}$ \\
\hline $\begin{array}{l}\text { Exposure counter } \\
\text { identifier } \\
\text { 3-digit counter }\end{array}$ & $\begin{array}{l}16 \text { possible codes } \\
\text { with reset to } 000\end{array}$ \\
\hline
\end{tabular}




\begin{tabular}{||l|l||}
\hline \multicolumn{2}{|c||}{ Instrument Description (contd) } \\
\hline Shutter speed & $\begin{array}{l}1 / 100 \mathrm{~S} \text { to } 1 / 1000 \mathrm{~S} \text { continuously } \\
\text { adjustable }\end{array}$ \\
\hline Aperture & f:4 to f:22, continuously adjustable \\
\hline $\begin{array}{l}\text { Data Recording Capabilities } \\
\text { Marginal Data } \\
\text { internal camera status }\end{array}$ & $\begin{array}{l}\text { automatic recording of aircraft } \\
\text { voltage, v/h. shutter setting } \\
\text { aperture etc. }\end{array}$ \\
& $\begin{array}{l}\text { from aircraft navigation system or computer } \\
\text { external data }\end{array}$ \\
any combination & of internal and external data \\
\hline
\end{tabular}

\subsection{Barr \& Stroud IR-18 Thermal Imager}

The Barr \& Stroud thermal imager is a passive thermal infrared sensor that is especially useful for nighttime reconnaissance of heat-generating targets. Operating much like a video camera, the imager is sensitive only to thermal infrared energy. Its lens is a dual, focal germanium telescope offering $2.5 \mathrm{X}$ or $9 \mathrm{X}$ power options. The system is cooled by a Joule-Thompson gaseous nitrogen unit. Data acquired with the IR-18 is recorded with a TEAC V-80AB-F. This high-resolution video recorder utilizes a Hi-8-mm format, which captures higher frequencies and bandwidths than those from a conventional VHS video recorder. Although this recorder is small and lightweight, its durable, frontloading design operates on unregulated $28 \mathrm{VDC}$, permitting aircraft or vehicular use.

\subsubsection{TEAC V-80AB-F Hi-8-mm Airborne Recorder Specifications}

\begin{tabular}{||l|l||}
\hline \multicolumn{2}{|c|}{ General Specifications } \\
\hline Capability & Record and Playback, Color and Black \& White \\
\hline Tape Type & Hi-8-mm videocassette \\
\hline Tape Format & Hi-8-mm \\
\hline Maximum Recording Time & 120 minutes \\
\hline Power Requirement & $28 \mathrm{VDC}(+4 \mathrm{~V},-8 \mathrm{~V})$ unregulated MIL-STD-704C \\
\hline Power Consumption & $\begin{array}{l}15 \text { watts (nominal) at 28VDC (55 watts with } \\
\text { optional heater) }\end{array}$ \\
\hline
\end{tabular}




\begin{tabular}{||l|l||}
\hline \multicolumn{2}{|c|}{ General Specifications (contd) } \\
\hline Dimensions & $\begin{array}{l}5.83 \text { in (W) } \times 4.73 \text { in (H) } \times 6.11 \text { in (D), excluding } \\
\text { connectors, knobs, and buttons }\end{array}$ \\
\hline Operational Position & All directions \\
\hline Installation & Vertical or horizontal, 4 ways \\
\hline Weight & Less than 3 kg \\
\hline Connectors & $\begin{array}{l}\text { Power: PT02E-10-6P type Control and Signal: } \\
\text { PT02E-18-32P type (Optional } \\
\text { MIL-STD-38999, Series 3 connectors available) }\end{array}$ \\
\hline
\end{tabular}

\begin{tabular}{|l|l||}
\hline \multicolumn{2}{|c|}{ Functional Specifications } \\
\hline Remote Controls (Discrete) & STOP, REC, STDBY, PLAY, FF, REW, EMK REC \\
\hline Remote Controls (RS-422) & $\begin{array}{l}\text { STOP, REC, STDBY, PLAY, FF, REW, SEARCH FWD, } \\
\text { SEARCH RVS, STILL, INTERVAL REC, EMK REC, } \\
\text { TIMER RESET }\end{array}$ \\
\hline Local Controls & $\begin{array}{l}\text { CASSETTE REMOVE, REC, STOP, STDBY, EMK } \\
\text { REC, REW, FF, PLAY }\end{array}$ \\
\hline Remote Indicator Signals (Discrete) & STOP, REC, STDBY, PLAY, EOT, DEW \\
\hline Remote Indicator Signals (RS-422) & $\begin{array}{l}\text { STOP, REC, STDBY, PLAY, FF, REW, SEARCH FWD, } \\
\text { SEARCH RVS, STILL, INTERVAL REC, EOT, BOT, } \\
\text { DEW, CASSETTE IN, UNTHREAD END, THREAD } \\
\text { MOTOR ON, TAPE COUNTER, ERROR, COMMAND } \\
\text { ERROR, PARITY/FRAMING ERROR }\end{array}$ \\
\hline Interface & Discrete or RS-422 Full Duplex \\
\hline
\end{tabular}




\begin{tabular}{||l|l||}
\hline \multicolumn{2}{|l|}{ Video } \\
\hline Video Signal Standard & EIA RS-170 or NTSC \\
\hline Bandwidth & $4 \mathrm{MGz}$ \\
\hline Horizontal Resolution & 400 -line nominal \\
\hline Linearity & 10 gray scale or better \\
\hline Signal-to-Noise Ratio & Better than 43 dB \\
\hline Input & $1.0 \mathrm{~V}$ p-p 75-ohm negative sync \\
\hline Level Control & Automatic gain control (AGC) \\
\hline Output & $1.0 \mathrm{~V}$ p-p 75-ohm negative sync \\
\hline S-Video Input & $1.0 \mathrm{~V}$ p-p (Y), 0.3V p-p (C), 75 ohm \\
\hline S-Video Output & $1.0 \mathrm{~V} \mathrm{p-p} \mathrm{(Y),0.3V} \mathrm{p-p} \mathrm{(C),} \mathrm{75-ohm}$ \\
\hline
\end{tabular}

\begin{tabular}{||l|l||}
\hline \multicolumn{2}{|l||}{ Audio } \\
\hline Number of Channels & One \\
\hline Input Level & $0.9 \mathrm{~V}$ p-p nominal, (-10 dbV) \\
\hline Input Impedance & $10 \mathrm{~K}$-ohm $20 \%$ \\
\hline Level Control & Automatic gain control \\
\hline Output Level & $0.9 \mathrm{~V} \mathrm{p}-\mathrm{p}(47 \mathrm{~K}$-ohm load) \\
\hline Bandwidth (Frequency Response) & $100 \mathrm{~Hz}$ to $10 \mathrm{KHz}$ \\
\hline Signal-to-Noise Ratio & Better than $40 \mathrm{~dB}$ \\
\hline
\end{tabular}




\begin{tabular}{||l|l|}
\hline \multicolumn{2}{|c|}{ Environmental Specifications } \\
\hline Storage Temperature & $-20^{\circ} \mathrm{C}$ to $+60^{\circ} \mathrm{C}$; MIL-STD-810D 501.2(I) and 502.2(I) \\
\hline Operating Temperature & $\begin{array}{l}-15^{\circ} \mathrm{C} \text { to }+55^{\circ} \mathrm{C} \text {; MIL-STD-810D 501.2(II) and 502.2(II) } \\
\left(-40^{\circ} \mathrm{C} \text { to }+55^{\circ} \mathrm{C} \text { with optional heater) }\right.\end{array}$ \\
\hline Altitude & $\begin{array}{l}\text { Sea level to } 50,000 \text { feet in an unpressurized, unsealed case; } \\
\text { MIL-STD-810D 500.2, operating }\end{array}$ \\
\hline Storage Humidity & $80 \%\left(34^{\circ} \mathrm{C}\right)$ to $20 \%\left(71^{\circ} \mathrm{C}\right) ;$ MIL-STD-810D 507.1(I) \\
\hline Operating Humidity & Zero to $95 \%$ relative humidity (non-condensing) \\
\hline Explosive Atmosphere & MIL-STD-810D 511.2(I) \\
\hline Vibration (operational) & $\begin{array}{l}\text { MIL-STD-810D 514.3 (use of proper shock mount is } \\
\text { recommended }\end{array}$ \\
\hline Acceleration (operational) & $10 \mathrm{G}$ s, MIL-STD-810D 513.3, crash safety (operating) \\
\hline $\begin{array}{l}\text { Radio Frequency Interference/ } \\
\text { Electromagnetic Interference }\end{array}$ & MIL-STD-461C \\
\hline Heater (optional) & Thermostat-initiated at $0^{\circ} \pm 5^{\circ} \mathrm{C}$ \\
\hline \hline
\end{tabular}

\subsection{CASI Hyperspectral Imager}

\subsubsection{Tape File Format}

A CASI raw data tape consists of Files and Filemarks. One Filemark is found after every file. Every File has a File Header at the beginning of the file and may contain numerous Frames.

A File Header contains 1024 bytes (1 sector) and is described below.

A Frame consists of one or more sectors composed of a Frame Header followed by one "scan line" of Spatial Mode or Spectral Mode data and then padded to the end of the last sector with ASCII null characters (i.e., binary zeros). The length of each Frame in bytes and sectors is defined in the File Header, as is the length of the Frame Header. The Frame Data is described below as well. 


\subsubsection{File Header Format}

The CASI file header consists of free-format ASCII fields, each separated by an ASCII null character. Each field, with the exception of the first field, consists of a keyword followed by data in ASCII (printable) format. The locations of the fields after the first field may appear in any order, however, they generally are found in the order shown in the example below.

The file header is 1024 bytes long beginning with the string "CasiFileHeader"; after the last field, the header is filled with ASCII nulls. The length of a file header is 1024 bytes.

\begin{tabular}{||l|l||}
\hline \multicolumn{2}{|c|}{ Sample CASI File Header } \\
\hline CasiFile Header & $\begin{array}{l}\text { Identifies the file as a CASI data file; } \\
\text { Marks the beginning of the file header. }\end{array}$ \\
\hline Serial Number NNN & $\begin{array}{l}\text { Serial number of the CASI on which the data were } \\
\text { recorded (used to relate calibration parameters to the } \\
\text { data); } \\
\text { Serial number NNN is read as: first digit is the series } \\
\text { number and the last two digits are the unit number. }\end{array}$ \\
\hline Version 1.52E & CASIIS (instrument software) version number \\
\hline Frame Header Length 64 & $\begin{array}{l}\text { The length of the frame headers in the current data file } \\
\text { in bytes. }\end{array}$ \\
\hline Date 19910906 & $\begin{array}{l}\text { System clock date when the file was written; } \\
\text { ANSI YYYY MM DD format. }\end{array}$ \\
\hline Time 13 06 10 390 & $\begin{array}{l}\text { Time the file was opened (F3 - ARM TAPE pressed); } \\
\text { provided by the system clock; format is hh mm ss ppp, } \\
\text { where "ppp" is milliseconds. }\end{array}$ \\
\hline Mode 1 & $\begin{array}{l}\text { Mode of instrument operation; } \\
\text { Modes are: Spatial (0), Spectral (1) or Calibration (2). }\end{array}$ \\
\hline Integration Time 1000 & $\begin{array}{l}\text { Integration Time in milliseconds from the instrument } \\
\text { configuration for this data file. }\end{array}$ \\
\hline MaxRows 288 & Maximum number of rows (in the spectral dimension). \\
\hline MaxColumns 612 & $\begin{array}{l}\text { Maximum number of columns (in the spatial dimension). } \\
\text { Note: not all of the columns are available for scene } \\
\text { information. }\end{array}$ \\
\hline Row1 943 & $\begin{array}{l}\text { Wavelength in nanometers for the first row of CCD } \\
\text { pixels. }\end{array}$ \\
\hline
\end{tabular}




\begin{tabular}{|c|c|}
\hline \multicolumn{2}{|c|}{ Sample CASI File Header (contd) } \\
\hline Row288 426 & $\begin{array}{l}\text { Wavelength in nanometers for the 288th row of CCD } \\
\text { pixels. }\end{array}$ \\
\hline G0 9.432092E +002 & $\begin{array}{l}G 0 \text { through } G 3 \text { are the constants in a fourth order } \\
\text { polynomial used to convert a } C C D \text { row number to a } \\
\text { wavelength. The general equation is of the form: } \\
\lambda=G 0+R \circ G 1+R^{2} \circ G 2+R^{3} \circ G 3 \\
\text { where } 1 \text { represents wavelength }(\mathrm{nm}) \text { and } R \text { represents the } \\
\text { (CCD row number }-\lambda) \text {; } \\
\text { These G-values are determined during the instrument } \\
\text { calibration process and are stored on the System Disk } \\
\text { provided with each calibration. }\end{array}$ \\
\hline $\mathrm{G} 1-1.9555689675 \mathrm{E}+000$ & See $\mathrm{G} 0$ above. \\
\hline G2 \&.0466699887E-004 & See $G 0$ above. \\
\hline G3 -5.6624412628E-007 & See G0 above. \\
\hline SpectralConfig 18292028864547 & $\begin{array}{l}\text { Regardless of the Mode used in data collection, all } \\
\text { configuration information for both Spectral Mode and } \\
\text { Spatial Mode are stored in the file header. } \\
\text { The Spectral Configuration fields are: Scene recovery } \\
\text { channel, Number of Looks less ExtraLooks, Look } \\
\text { spacing, Center Look direction, Number of bytes per } \\
\text { frame, Number of sectors per frame. }\end{array}$ \\
\hline $\begin{array}{l}\text { SpatialConfig } 9464997104122124 \\
137144145153161167188194215 \\
2202572631108011\end{array}$ & $\begin{array}{l}\text { See SpectralConfig above; } \\
\text { The Spatial Configuration fields are: Number of Bands } \\
\text { N, Start Row for Band } 1 \text {, End Row for Band } 1, \ldots \text { Start } \\
\text { Row for Band N, End Row for Band N, Number of } \\
\text { Bytes per frame, Number of Sectors per frame. }\end{array}$ \\
\hline Flight ID & $\begin{array}{l}\text { Ten lines of Flight Identification information are } \\
\text { available for user defined information. }\end{array}$ \\
\hline Extra Looks 3 & $\begin{array}{l}\text { The number of Extra Look directions (currently } \\
\text { Electronic Offset, Dark Current and Incident Sensor). }\end{array}$ \\
\hline Irradiance Sensor 35 & $\begin{array}{l}\text { Incident Sensor (formerly termed the "irradiance Sen- } \\
\text { sor") column position varies from instrument to } \\
\text { instrument. }\end{array}$ \\
\hline
\end{tabular}




\subsubsection{Frame Data Format}

If a frame ("image scan line") contains X bytes of data, then the first sector (1024 bytes) of the data frame consists of FrameHeaderLength bytes of frame header and the balance is filled with (1024 FrameHeaderLength bytes of ) frame data.

The remaining (X - [1024 - FrameHeaderLength] bytes of) data are stored in successive 1024 byte sectors.

\subsubsection{Frame Header}

The frame header currently consists of a four-byte sequence ID, a four-byte date, and a five-byte time stamp. The remaining bytes in this header are not currently defined.

2.3.3.1.1 Sequence ID Field. The sequence ID is a signed 16-bit integer that identifies the frame within the file. The first frame has sequence ID 0 , and subsequent frames have a successively higher sequence ID. A 16-bit integer consists of two bytes in low byte -high byte order.

2.3.3.1.2 Date Field. The date field consists of four bytes; the year since 1980, the month, the date, and the day of the week. (Note that the day of the week may not contain valid data.)

2.3.3.1.3 Time Stamp Field. The time stamp consists of five bytes: hours, minutes, seconds, tens of milliseconds, and tenths of milliseconds.

\subsubsection{Spatial Mode Data Format}

The Spatial Mode data contains "Number of Bands" spectral bands, each containing "MaxColumns" pixels. These pixels are 16-bit values, in low byte - high byte order. The data is ordered in the file band by band starting at the red end of the spectrum. Within each band there are 612 pixels, which are ordered such that pixels from the right-hand side of the scene (view looking down from the aircraft) come first.

\subsubsection{Spectral Mode Data Format}

The Spectral Mode data contains both "ExtraLooks" plus the "NumberofLooks" look directions, each containing "MaxRows" pixels, and one single row band (Scene Recovery Channel) of length "MaxColumns" interleaved within the look directions. These pixels are 16-bit values, in low byte high byte order.

\subsubsection{Configuration File Format}

All values in the Configuration File are in ASCII printable form encoded as decimal values. All values in the .CCF file are stored on a single line and separated by spaces. 


\begin{tabular}{|c|c|}
\hline \multicolumn{2}{|c|}{ Configuration File Format } \\
\hline$<$ MODE $>$ & Initial mode: Spectral (0) or Spatial (1) \\
\hline$<$ DISP_BAND $>$ & $\begin{array}{l}\text { Initial band in spatial mode that is to be displayed } \\
\text { when the Run Screen is entered. }\end{array}$ \\
\hline$<$ MOST_SIG_BIT $>$ & $\begin{array}{l}\text { The most significant bit used to display scene data on } \\
\text { the Run Screen (11 means that the maximum display } \\
\text { value is } 4095 \text { ). }\end{array}$ \\
\hline $\begin{array}{l}<\text { MODE_IT[0] }><\text { MODE_IT[1] < MO } \\
\text { DE_IT[2]> }\end{array}$ & $\begin{array}{l}\text { An array of integration times (in milliseconds) used } \\
\text { for Spectral ( } 0) \text {, Spatial (1) and Calibration (2) } \\
\text { modes. }\end{array}$ \\
\hline $\begin{array}{l}<\text { MODE_MIT[0] }><\text { MODE_MIT[1] }> \\
<\text { MODE_MIT[2] }>\end{array}$ & $\begin{array}{l}\text { An array of MINIMUM allowable integration time } \\
\text { (in milliseconds) for Spectral (0), Spatial (1), and } \\
\text { Calibration (2) modes. }\end{array}$ \\
\hline$<\mathrm{IT}>$ & Current integration time in milliseconds. \\
\hline$<\mathrm{MIT}>$ & Current minimum integration time in milliseconds. \\
\hline$<$ TRACK_RECOV_ROW $>$ & $\begin{array}{l}\text { Row number of the Spatial Recovery Channel where } \\
\text { a full spatial resolution image of a single spectral row } \\
\text { (monochromatic) is obtained during the spectral mode } \\
\text { of operation. }\end{array}$ \\
\hline$<$ NO_LOOK_DIRS $>$ & $\begin{array}{l}\text { Number of programmed Look Directions (excluding } \\
\text { ExtraLooks). }\end{array}$ \\
\hline$<$ LOOK_SPACING $>$ & $\begin{array}{l}\text { The number of spatial columns between each look } \\
\text { direction. }\end{array}$ \\
\hline$<$ CENTRE_LOOK_DIR > & $\begin{array}{l}\text { The column number of the center of the look direc- } \\
\text { tion set. }\end{array}$ \\
\hline$<$ NUM_OF_BANDS $>$ & Number of spectral bands defined in Spatial Mode. \\
\hline$<$ START_ROW[1] $><$ END_ROW[1] $>$ & $\begin{array}{l}\text { A pair of values that define the CCD rows } \\
\text { corresponding to each spectral band. }\end{array}$ \\
\hline $\begin{array}{l}<\text { START_ROW[MAX] }><\text { END_ROW[ } \\
\text { MAX] }>\end{array}$ & $\begin{array}{l}\text { There are MAX number of these bands permitted. } \\
\text { MAX is currently defined to be } 15 \text {. All } 15 \text { sets are } \\
\text { defined here, but unused bands are defined as pairs } \\
\langle 0,0\rangle\end{array}$ \\
\hline
\end{tabular}




\subsection{First Generation Intensified Monochrome CCD Camera}

The COHU 5560 low light camera is a highly sensitive, high-resolution CCD camera. This camera, designed for low light conditions, uses a first generation image intensifier, which is fiberoptically coupled to the CCD image. A summary of the camera's characteristics follows.

Images are recorded with the TEAC V-80AB-F. This high-resolution video recorder utilizes a Hi-8-mm format, which captures higher frequencies and bandwidths than those from a conventional VHS. This is the same recorder used for the Barr and Stroud thermal imager. Its characteristics are given in Section 2.2.1.

\begin{tabular}{||l|l||}
\hline \multicolumn{2}{|c|}{ Monochrome 5560 CCD Camera } \\
\hline Resolution & $\begin{array}{l}520 \text { TV lines horizontal } \\
\text { > 350 TV lines vertical }\end{array}$ \\
\hline Sensitivity & $\begin{array}{l}2854 \mathrm{~K} \text { faceplate illumination } \\
\text { Full Video }\end{array}$ \\
Useable Picture & $0.0001 \mathrm{fc}(0.001$ lux $)$ \\
\hline Auto Black & Maintain set-up level at $7.5 \pm 5$ IRE units if picture \\
& contains at $10 \%$ black \\
\hline Signal-to-Noise Ratio & $40 \mathrm{~dB}$ unweighted, with AGC low and high voltage \\
& low, 0.01 fc faceplate illumination, 45 dB \\
\hline
\end{tabular}

\subsection{SONY DXC-750 3-CCD Video Camera}

The DXC-750 3-CCD video camera uses high-resolution CCDs, each frame having 380,000 pixel elements. This low-power consumption camera also has low lag and a high resistance to image burning with no deflection distortion. Electronic shutter options enable the camera to produce clear images in still or slow-motion playback even when the objects are moving at very high speed.

\begin{tabular}{||l|l||}
\hline \multicolumn{2}{|c|}{ Specifications } \\
\hline Pick-up Device & Interline Transfer CCD \\
\hline Picture Elements & $768(\mathrm{H}) \times 493(\mathrm{~V})$ \\
\hline Sensing Area & 8.8 -mm x 6.6 mm \\
\hline Scanning System & 525 lines, 60 fields/sec. 2:1 interlace \\
\hline
\end{tabular}




\begin{tabular}{||l|l||}
\hline \multicolumn{2}{|c||}{ Specifications (contd) } \\
\hline Sync System & Internal or external with VBS HD/VD \\
\hline Horizontal Frequency & $15.73 \mathrm{kHz}$ \\
\hline Vertical Frequency & $59.94 \mathrm{kHz}$ \\
\hline Horizontal Resolution & $700 \mathrm{TV}$ lines \\
\hline Lens Mount & Bayonet \\
\hline Sensitivity & 2,000 lux with F5.6, $89.9 \%$ reflectance \\
\hline Minimum Illumination & 20 lux (F1.4 lens, $+18 \mathrm{~dB}$ gain) \\
\hline Gain Selection & $0,+9,+18 \mathrm{~dB}$ selectable \\
\hline Electronic Shutter & $1 / 125,1 / 250,{ }^{1 / 500},{ }^{1} / 1000,1 / 2000,1 / 4000,1 / 10000$ \\
\hline Detail Level Adjustment & Continuously variable \\
\hline Linear Matrix & ON/OFF selectable \\
\hline Gamma & ON/OFF selectable \\
\hline S/N Ratio & $60 \mathrm{~dB}$ \\
\hline Operating Temperature & $-5^{\circ} \mathrm{C}$ to $+45^{\circ} \mathrm{C}$ \\
\hline Storage Temperature & $-20^{\circ} \mathrm{C}$ to $+60^{\circ} \mathrm{C}$ \\
\hline Power Consumption & $28 \mathrm{~W}$ \\
\hline Maximum Cable Length & $100 \mathrm{~m}$ \\
\hline White Balance, Black Balance & AUTO and MANUAL: R, B (GAIN, PEDESTAL) \\
\hline Color Temperature & $3,200^{\circ} \mathrm{K} / 5,600^{\circ} \mathrm{K}$ selectable \\
\hline Color Bar Generator & Full field \\
\hline Weight & Camera head: \\
& $600 \mathrm{~g}(1.32 \mathrm{lb})($ without $2.5 \mathrm{~m}$ cable \\
& Camera Control Unit: $2.5 \mathrm{~m}$ cable \\
\hline & $6.5 \mathrm{~kg}(14.3 \mathrm{lb})$ \\
\hline
\end{tabular}

Acquired data is recorded with the SONY DVR-2 Portable Digital Cassette VTR. Utilizing a digital recorder removes dropouts which may occur with an analog system. 


\begin{tabular}{||l|l||}
\hline \multicolumn{2}{|l|}{ General Specifications } \\
\hline Power Requirements & 12 V DC \\
\hline Power Consumption & Approximately $65 \mathrm{~W}$ \\
\hline Operating Temperature & $0^{\circ} \mathrm{C}$ to $+40^{\circ} \mathrm{C}$ \\
\hline Storage Temperature & $-20^{\circ} \mathrm{C}$ to $+60^{\circ} \mathrm{C}$ \\
\hline Humidity & Less than $90 \%$ (relative humidity) \\
\hline Weight & $\begin{array}{l}\text { Approximately } 12 \mathrm{~kg} \text { (without batteries and tape) } \\
\text { Approximately } 16 \mathrm{~kg} \text { (including batteries and case) }\end{array}$ \\
\hline Dimensions & 14 in (W), $63 / 8$ in (H), 16 5/8 in (D) \\
\hline Recording Format & SMPTE D-2 format \\
\hline Tracks/Channels & $\begin{array}{l}\text { Digital video and audio (4 channels) } 6 \text { tracks/1 field } \\
\text { Analog audio (cue) } 1 \text { track } \\
\text { Time code } \\
\text { CTL }\end{array}$ \\
\hline Tape Speed & 131.7 mm/sec \\
\hline Writing Speed (Relative Speed) & $27.387 \mathrm{~m} /$ sec \\
\hline Record Time & $\begin{array}{l}\text { Max. } 94 \text { minutes with M cassette } \\
\text { Max. 32 minutes with S cassette }\end{array}$ \\
\hline Cassette type & D-1 cassette (M or S size) \\
\hline Recommended Tape & Sony metal (1500 Oe) tape or equivalent \\
\hline Error Correction & Correction and concealment (Reed-Solomon code) \\
\hline Fast Forward/Rewind Time & $\begin{array}{l}\text { Within } 150 \text { sec. (with } 32 \text { minute tape) Within 360 sec. } \\
\text { (with } 94 \text { minute tape) }\end{array}$ \\
\hline Search Mode & \pm 20 times normal playback \\
\hline Continuous Operation Time & Approximately 100 minutes (with two BP-90A batteries) \\
\hline \hline & \\
\hline
\end{tabular}




\begin{tabular}{||l|l||}
\hline \multicolumn{2}{|c|}{ Video } \\
\hline Sampling Frequency & $14.3 \mathrm{MHz}$ \\
\hline Quantization & 8 bits/I, Q axis sampling \\
\hline Channel coding & $\mathrm{M}^{2}$ \\
\hline Video Bandwidth & 0 to $5.5 \mathrm{MHz} \pm 0.5 \mathrm{~dB}, 6 \mathrm{MHz} \pm ? \mathrm{~dB}$ \\
\hline Signal-to-Noise Ratio & $54 \mathrm{~dB}$ \\
\hline Differential Gain & Less than $2 \%$ \\
\hline Differential Phase & Less than $1^{\circ}$ \\
\hline Moire & 0 \\
\hline Y/C Delay & Less than 15 nsec \\
\hline Tilt (Horizontal \& Vertical) & Less than $1 \%$ \\
\hline Low Frequency Linearity & Less than $2 \%$ (including quantization noise) \\
\hline $\begin{array}{l}\text { Transient Response "K" } \\
\text { Factor (2T Pulse) }\end{array}$ & Less than $1 \%$ \\
\hline Input Level Adjustable Range & \pm 3 dB \\
\hline
\end{tabular}

\begin{tabular}{||l|l||}
\hline \multicolumn{2}{|c|}{ Digital Audio (DA 1 to 4 Channels) } \\
\hline Sampling Frequency & $48 \mathrm{kHz}$ (synchronized to video) \\
\hline Quantization & $16 \mathrm{bits} /$ sample \\
\hline Frequency Response & $20 \mathrm{~Hz}$ to $20 \mathrm{kHz}+0.5 \mathrm{db}-1.0 \mathrm{~dB}$ \\
\hline Dynamic Range & More than $90 \mathrm{~dB}$ (at $1 \mathrm{kHz}$, emphasis ON) \\
\hline Distortion & Less than $0.05 \%$ (at $1 \mathrm{kHz}$, emphasis ON, operating level) \\
\hline Crosstalk & Less than $-80 \mathrm{~dB}$ (at $1 \mathrm{kHz}$, between any two channels) \\
\hline Wow \& Flutter & Below measurable limit \\
\hline Headroom & $20 \mathrm{~dB}$ \\
\hline Emphasis & $\mathrm{T}_{1}=50 \mu \mathrm{sec} / \mathrm{T}_{2}=15 \mu \mathrm{sec},(\mathrm{ON} / \mathrm{OFF}$ selectable) \\
\hline Input Gain Range & $-\infty$ to $+12 \mathrm{~dB}$ \\
\hline
\end{tabular}




\begin{tabular}{||l|l||}
\hline \multicolumn{2}{|c|}{ Analog Audio } \\
\hline Frequency Response & $100 \mathrm{~Hz}$ to $12 \mathrm{kHz} \pm 3 \mathrm{~dB}$ \\
\hline Signal to Noise Ratio & Better than $44 \mathrm{~dB}$ (at 3\% distortion) \\
\hline Distortion & Less than $3 \%$ (at $1 \mathrm{kHz}$ operating level) \\
\hline Wow \& Flutter & Less than $0.2 \%(0.5$ to $200 \mathrm{~Hz}, \mathrm{NAB}$ unweighted) \\
\hline Operating Level & $\begin{array}{l}+8 .+4.0 .-22 \mathrm{dBm} \text { adjustable (LINE IN/OUT) } \\
<\text { Factory set }+8 \mathrm{dBm}>-60 \mathrm{dBs} \text { (MC INPUT) }\end{array}$ \\
\hline Input/Output Level Range & $-\infty$ to $+6 \mathrm{~dB}$ \\
\hline
\end{tabular}

\begin{tabular}{|c|c|}
\hline \multicolumn{2}{|c|}{ Input/Output Signal } \\
\hline $\begin{array}{l}\text { Video } \\
\text { Input } \\
\text { Analog } \\
\text { Output } \\
\text { Monitor } \\
\end{array}$ & $\begin{array}{l}1.0 \pm 0.3 \mathrm{~V} \text { p-p } 75 \text { ohms } \\
1 \mathrm{~V} \mathrm{p-p} 75 \text { ohms }\end{array}$ \\
\hline $\begin{array}{l}\text { Audio } \\
\text { Input } \\
\text { Analog (CH 1,2,3,4) } \\
\text { Cue } \\
\text { Output } \\
\text { Monitor L/R } \\
\text { Headphones }\end{array}$ & $\begin{array}{l}\text { Line Max. }+28 \mathrm{dBm} \text { (Nominal }+8 \mathrm{dBm} \text { ) } \\
\text { Mic Max. }-44 \mathrm{dBs} \text { (Nominal }-60 \mathrm{dBs}) \\
\text { Line Max. }+18 \mathrm{dBm} \text { (Nominal }+8 \mathrm{dBm} \text { ) } \\
\text { Mic Max. }-44 \mathrm{dBs} \text { (Nominal }-60 \mathrm{dBs}) \\
\text { Max }+28 \mathrm{dBm} \text { (Nominal }+8 \mathrm{dBm}) \\
\text { Variable level control by VR }\end{array}$ \\
\hline $\begin{array}{l}\text { Time Code } \\
\text { Input } \\
\text { Output }\end{array}$ & $\begin{array}{l}2.4 \mathrm{~V} \pm 1.4 \mathrm{~V} \mathrm{p}-\mathrm{p}, 10 \mathrm{k} \text { ohms, balanced } \\
2.4 \mathrm{Vp}-\mathrm{p}, \text { low impedance, balanced }\end{array}$ \\
\hline
\end{tabular}




\subsection{Airborne Multispectral Scanner ABS/AMS}

The ABS/AMS system data is recorded onto standard 8-mm video tape cartridges. The data structures on tape are files that are created each time the operator issues a record command from the digitizer. Each file will start with a file header and end with a file mark. A new file is started at the current end-of-data, which is indicated by two file marks; one of these marks is removed whenever a new file is written. The tape between the file header and file mark contains an arbitrary number of lines or frames of scanner data. Each frame starts with a frame header followed by blocks of data, one for each channel. The length of each block of data depends on the detector IFOV. When a full fieldof-view and $2.5 \mathrm{mrad}$ detectors are selected, the data from each channel is 720 words long. These 720 words consist of 714 digitized scene pixels, 2 digitized reference source values, and 4 ancillary words. Each data word on tape has a width of 8 bits. If the operator selects 12-bit operation, a third channel is included for each pair of channels and is made up of the least significant 4 bits from the two channels.

\subsubsection{General File Structure}

Each file starts with a 2048 word header. The first four words are the hexadecimal pattern 5548 46 AA. The complete format is described below.

Each frame of scanner data, which represents all the data from on rotation of the scan mirror, starts with a 70-word header. Similar to the file header, the first four words are the hexadecimal pattern 56 A5 A6 AF. The remaining words contain information current at the start of the scan line such as time and date, the scan line number (incremented each line), navigation data, external data, and thermal reference settings.

Following the frame header are blocks of channel data, one for each detector channel (8-bit mode). The first four words of each block are the gains and offset settings for that channel. Word five is the detector value for the first reference. The last word is the detector value for the second reference. Between the two reference words are the scene data. The standard size of each channel block is 720 words including the four starting words and the two reference values. The current size options are:

\begin{tabular}{|c|c|c|}
\hline TFOV (degrees) & Detector Size (mrad) & Size (words) \\
\hline 86 & 5.00 & 360 \\
\hline 86 & 2.50 & 720 \\
\hline 86 & 1.25 & 1440 \\
\hline
\end{tabular}


The size of each channel block is constant within any given file on tape.

For 12-bit operation, the least significant 4 bits from each channel are combined to make up a third channel with the channel 1's LSBs in the most significant 4 bits of channel 3 and the channel 2 LSBs in the least significant 4 bits. The gain and offset words of this combined channel will be zero.

\begin{tabular}{||l|l|c||}
\hline \multicolumn{2}{|c|}{ Tape Format (8-Bit Mode, 2.5 mrad) } \\
\hline \multirow{4}{*}{ Scan Line 1 } & Frie Header & 2048 bytes \\
\cline { 2 - 4 } & Channel 1 & 70 bytes \\
\cline { 2 - 4 } & Channel 2 & 720 bytes \\
\hline \multirow{3}{*}{ Scan Line 2 } & Frame Header & 720 bytes \\
\cline { 2 - 4 } & Channel 1 & 70 bytes \\
\cline { 2 - 4 } & Channel 2 & 720 bytes \\
\hline$\bullet$ & $\bullet$ & 720 bytes \\
\hline$\bullet$ & $\bullet$ & $\bullet$ \\
\hline$\bullet$ & $\bullet$ & $\bullet$ \\
\hline \multirow{3}{*}{ Scan Line n } & Frame Header & 70 bytes \\
\cline { 2 - 4 } & Channel 1 & 720 bytes \\
\cline { 2 - 4 } & Channel 2 & 720 bytes \\
\hline & EOF & - \\
\hline
\end{tabular}




\begin{tabular}{|c|c|c|}
\hline \multicolumn{3}{|c|}{ Tape Format (12-Bit Mode, 2.5 mrad) } \\
\hline \multicolumn{2}{|c|}{ File Header } & 2048 bytes \\
\hline \multirow[t]{4}{*}{ Scan Line 1} & Frame Header & 70 bytes \\
\hline & Channel 1 & 720 bytes \\
\hline & Channel 2 & 720 bytes \\
\hline & Channel 3 & 720 bytes \\
\hline \multirow[t]{4}{*}{ Scan Line 2} & Frame Header & 70 bytes \\
\hline & Channel 1 & 720 bytes \\
\hline & Channel 2 & 720 bytes \\
\hline & Channel 3 & 720 bytes \\
\hline$\bullet$ & $\bullet$ & $\bullet$ \\
\hline - & $\bullet$ & $\bullet$ \\
\hline$\bullet$ & $\bullet$ & - \\
\hline \multirow[t]{5}{*}{ Scan Line $\mathbf{n}$} & Frame Header & 70 bytes \\
\hline & Channel 1 & 720 bytes \\
\hline & Channel 2 & 720 bytes \\
\hline & Channel 3 & 720 bytes \\
\hline & EOF & - \\
\hline
\end{tabular}




\subsubsection{Detailed File Structure}

\subsubsection{File Header}

The file header is described in the following table.

\begin{tabular}{|c|c|c|}
\hline \multicolumn{3}{|c|}{ File Header } \\
\hline Word & Name & Contents \\
\hline $1-4$ & Start of File & 4-word hexadecimal pattern $554846 \mathrm{AA}$ \\
\hline $5-7$ & Version Number & ABS/AMS software revision number in ASCII. \\
\hline 8 & Header Size & Binary value. Currently 70 decimal. \\
\hline 9 & Collection Mode & $\begin{array}{l}\text { Scanner collection mode (binary): } \\
\text { D7 reserved } \\
\text { D6 }=8 / 12 \mathrm{bits}, 1=12 \mathrm{bits}, 0=8 \mathrm{bits} \\
\text { D5 }=\text { TFOV }, 1=86 \mathrm{deg}, 0=43 \mathrm{deg} . \\
\text { D4,D3 = sample interval } \\
00=1.25 \mathrm{mrad}, 01=2.5 \mathrm{mrad} \\
10=5 \mathrm{mrad} \text {. } \\
\text { D2,D2,D0 }=\text { scan speed, } \\
000=100 \mathrm{sps}, 001=50 \mathrm{sps}, 010= \\
25 \mathrm{sps}, 011=12.5 \mathrm{sps}, 100=6.25 \mathrm{sps} \text {. }\end{array}$ \\
\hline 10,11 & Frame Size & $\begin{array}{l}\text { Binary value. Number of words in each fame } \\
\text { including the frame header. }\end{array}$ \\
\hline 12 & File Number & $\begin{array}{l}\text { Binary value. File number, } 0 \text { for first file on tape. } \\
\text { Increments for each new file. }\end{array}$ \\
\hline $13-18$ & Date and Time & $\begin{array}{l}\text { Values taken at start of record. Six words BCD of } \\
\text { form ddmmyy and hhmmss. }\end{array}$ \\
\hline
\end{tabular}




\begin{tabular}{|c|c|c|}
\hline \multicolumn{3}{|c|}{ File Header (contd) } \\
\hline 19-102 & Detector Information Words & $\begin{array}{l}\text { Twelve 7-byte words for each channel. The standard } \\
\text { ABS uses the first } 2 \text { only ( } 14 \text { bytes), for channels } 1 \\
\text { and } 2 \text { respectively. The format for each 7-byte word } \\
\text { is: } \\
\text { Word 1: } \\
\quad \text { D7,D6,D5 = Type: } 0=\mathrm{Si} \text {, } \\
\qquad 1=\mathrm{MCT}, 2=\mathrm{InSb}, 3-7 \text { reserved. } \\
\qquad 4, \mathrm{D} 3, \mathrm{D} 2=\mathrm{reserved:} 0 \\
\quad \mathrm{D} 1, \mathrm{D} 0=\mathrm{IFOV}: 0=1.25,1=2.5 \text {, } \\
\quad 2=5.0,3=\text { fault } \\
\text { Word } 2,3,4: \text { Upper band edge (ASCII) } \\
\text { Word 5,6,7: Lower band edge (ASCII) } \\
\text { For MCT and InSb: values between } 100 \text { and } 200 \\
\text { are tenths of microns; values between } 200 \text { and } 999 \\
\text { are hundredths of microns. } \\
\text { For Si: values between } 100 \text { to } 200 \text { are } 10 \mathrm{~nm} \\
\text { increments; } 200 \text { to } 999 \text { are } 1 \mathrm{~nm} \text { increments. }\end{array}$ \\
\hline 103,104 & Channel & $\begin{array}{l}\text { The least significant bit of word } 103 \text { indicates Ch } 1 \\
\text { is active up to D3 of word } 104 \text { for channel } 12 \text {. }\end{array}$ \\
\hline $105-256$ & Reserved & \\
\hline $257-1024$ & ARINC Format Structure & $\begin{array}{l}24 \text { fields of } 32 \text { bytes. Each field will define the } \\
\text { format of one label of the ARINC Raw Data. This } \\
\text { information is used to decode the Nav Data. }\end{array}$ \\
\hline $1025-2048$ & Comments & $\begin{array}{l}\text { Future upgrade for ASCII text entered by the } \\
\text { operator prior to starting the record for the current } \\
\text { file. }\end{array}$ \\
\hline
\end{tabular}

\subsubsection{Frame Header}

The frame header is repeated at the beginning of each scan line and is currently set to 70 bytes long. Reference to file header word 9 should be made to ensure that the current value is used. The revision number reflects any changes made. 


\begin{tabular}{|c|c|c|}
\hline \multicolumn{3}{|c|}{ Frame Header } \\
\hline Word & Name & Contents \\
\hline $1-4$ & Start of Frame & $\begin{array}{l}\text { 4-word hexadecimal pattern with } 56 \text { in word } 1 \\
\text { through } 4 .\end{array}$ \\
\hline $5-7$ & Scan Line Count & 3-word unsigned binary value. \\
\hline $8-13$ & Date and Time & $\begin{array}{l}\text { Repeat of format in file header. Time resolution } \\
\text { is to nearest second. }\end{array}$ \\
\hline $14-22$ & Standard Nav Data & $\begin{array}{l}\text { Three } 3 \text {-byte words of navigation data from the } \\
\text { nav data interface. The six words are: } \\
\text { Latitude, } \pm \pi \text { radians, } 18 \text { bits } 2 \text { 's comp } \\
\text { Longitude, } \pm \pi \text { radians, } 18 \text { bits } 2 \text { 's comp } \\
\text { Altitude, } 0 \text { to } 131,072 \text { feet ASL, } 17 \text { bits }\end{array}$ \\
\hline $23-38$ & Nav Raw Data & $\begin{array}{l}\text { A complete 4-byte representation of all data with } \\
\text { ARINC label received by the nav interface, } \\
\text { including ARINC label. These words allow for } \\
\text { the recovery of any other information not } \\
\text { included in the list of Standard Nav Data. The } \\
\text { ARINC label indicates the content of the data. } \\
\text { Labels may not be in order. No attempt is made } \\
\text { to time correlate the information. Each value is } \\
\text { the most recently received. This data is } \\
\text { completely synchronous with the scan speed and } \\
\text { sampling for inclusion in these words. }\end{array}$ \\
\hline $39-46$ & Reserved & \\
\hline $47-48$ & Roll Correction & $\begin{array}{l}\text { 14-bit representation of the system roll } \\
\text { correction. Zero indicates no roll. Each count } \\
\text { of the most significant } 14 \text { bits represents a roll } \\
\text { value of } 360 \text { degrees } 24000\end{array}$ \\
\hline $49-50$ & Pitch (optional) & $\begin{array}{l}\text { 15-bit representation of aircraft pitch. Each } \\
\text { count represents a value of } 360 \text { degrees } / 65536 \text {, } \\
\text { using the full 16-bit value. }\end{array}$ \\
\hline $51-54$ & External Data & $\begin{array}{l}\text { 32-bit map of the data present on the digitizer } \\
\text { rear panel connector J10. }\end{array}$ \\
\hline $55-58$ & Aux Ext Data (optional) & $\begin{array}{l}\text { For Aux External Data. 0's unless defined } \\
\text { otherwise. }\end{array}$ \\
\hline
\end{tabular}




\begin{tabular}{|c|l|l||}
\hline \multicolumn{2}{|c|}{ Frame Header (contd) } \\
\hline $59-62$ & Thermal Reference Settings & $\begin{array}{l}\text { Two 16-bit values representing the measured } \\
\text { temperatures of the two thermal references. A } \\
\text { value of 0 = 0 degrees C. The resolution is 1/16 } \\
\text { degree, the least significant 4 bits of each value } \\
\text { are always zero. }\end{array}$ \\
\hline 63 & File Number & Current file number. \\
\hline 64 & Header Size & Size of the frame header. \\
\hline 65 & Collection mode & Scanner collection mode. \\
\hline $66-67$ & Frame Size & Total number of words in each frame. \\
\hline $68-70$ & Reserved & \\
\hline
\end{tabular}

\subsubsection{Channel Data}

The first block (nominally 720 words) is the data for the lowest channel number recorded, followed by the data for other channels in order. If in the 12-bit mode, a third block follows, which is the least significant 4 bits for the preceding pair. The lowest channel number occupies the most significant 4 bits of the confined channel. Each channel block has the following structure.

\begin{tabular}{|c|c|c|}
\hline \multicolumn{3}{|r|}{ Channel Data } \\
\hline Word & Name & Contents \\
\hline 1 & Reference Gain & $\begin{array}{l}\text { The gain (potentially different than the scene gain) } \\
\text { applied while the detectors are viewing the references. } \\
\text { The value of this word for any combined channel is } \\
\text { always zero. }\end{array}$ \\
\hline 2 & Scene Gain & $\begin{array}{l}\text { 8-bit binary value representing an operator set gain of } \\
\text { 0-MAXGAIN. MAXGAIN varies from channel to } \\
\text { channel and from system to system. The value of } \\
\text { MAXGAIN is determined during system ATP. This } \\
\text { gain is applied while the detectors are viewing the } \\
\text { scene. The value of this word for channel } 3 \text { is always } \\
\text { zero. }\end{array}$ \\
\hline
\end{tabular}




\begin{tabular}{|c|c|c|}
\hline \multicolumn{3}{|c|}{ Channel Data (contd) } \\
\hline 3 & Offset & $\begin{array}{l}\text { 8-bit binary value representing an offset added after the } \\
\text { gain value in words } 1 \text { and } 2 \text {. A decimal value of } 128 \\
\text { represents no offset. The values can range between } \\
\text { VMAX and -VMAX. VMAX for each channel can be } \\
\text { found in the system ATP. Combined channels will } \\
\text { show zero; same as above words } 1 \text { and } 2 \text {. }\end{array}$ \\
\hline 4 & Scan Line Number LSB & $\begin{array}{l}\text { LSB of the scan line number. This provides a } \\
\text { convenient marker in the data when viewing it with the } \\
\text { monitor oscilloscope. }\end{array}$ \\
\hline 5 & REF1 & $\begin{array}{l}\text { The digitized detector value while viewing the first } \\
\text { thermal reference source. For non-thermal detectors } \\
\text { this represents zero energy. }\end{array}$ \\
\hline 6-LAST-1 & Scene & $\begin{array}{l}\text { The digitized detector value measured while viewing } \\
\text { the scene. }\end{array}$ \\
\hline LAST & REF2 & $\begin{array}{l}\text { The digitized detector value measured while viewing } \\
\text { the second thermal reference source. For non-thermal } \\
\text { detectors this represents zero energy. }\end{array}$ \\
\hline
\end{tabular}

\subsubsection{End of File}

When recording is terminated, the current frame is completed and an end-of-file mark written. An arbitrary number of zeros will end the file to fill out the current recorder block.

\subsubsection{File Mark}

A file mark will be written at the end of each file. This mark is written on the tape by the recorder when commanded by the Digitizer. This mark is identified by the recorder and will not appear in the data stream. The end of each record operation writes two file marks to signify the end of valid data. Starting a new record operation removes the second file mark and starts a new file. Data past a double file mark should be ignored. 


\subsection{Effluent Species Pod (Pod 3)}

\subsection{Echelle Grating Spectrometer}

The Echelle Grating Spectrometer data are available at three levels of analysis: pixel, spectrum, and chemical mixture. The data are acquired on a two-dimensional array detector having wavelength as one axis and grating order as the second axis. The analog signal intensity from each pixel is digitized by a 12-bit ADC and stored in a $256 \times 256$ integer array. Pixels can be read out sequentially from the entire array or individual pixel columns may be randomly addressed and read out. Operating (e.g., exposure time) and calibration (intensity, wavelength) data can be stored along with the spectral data. This defines the lowest level at which the raw data are available. Specialized internal cards in an 80386-based computer running MS-DOS are used to operate the detector and to read out and process the data. Custom software from the detector manufacturer is used to operate the detector and collect the data. Data may be integrated on the detector array or multiple spectra can be read out and co-added in the computer's memory. It is anticipated that a full data set will be collected every 1 to 100 seconds. Data storage will be on an internal ruggedized hard disk or on an external drive such as an Exabyte $2.5 \mathrm{~GB}$ 8-mm tape unit.

The wavelength calibration of each pixel in the stored array is used to assemble a linear spectrum of the measured signal intensity (absorption) versus wavelength. This representation is the most scientifically useful form of the data. The data can be further reduced as necessary by performing a search of library spectra to determine the identity and concentration of the chemical compounds found in the measured spectrum.

The image file header format is 256 words ( 512 bytes) long. A sample $C$ program definition of a header structure for storing data is shown for a revision 1 image header. The image data follow the header, and each pixel value intensity takes 2 bytes $=1$ word per pixel (data stored as integers). Typically, the bytes are swapped (ByteSwap $=0000$ ) so that the most significant byte (MSB) follows the least significant byte (LSB). The image header information is stored in the order shown below.

Note that if NumFramesSummed is greater than 1, then the data will be LONG integers and the data won't be byte swapped even though the header may be byte swapped. The only way any of your data may currently have multiple frames summed (rather than averaged) is by using the User Software module and incrementally linking it to the main program. 
\#define Header_Size $256 / *$ \# of WORDs in the ImageHeader - see below *l

struct IMAGE_HEADER \{

int ByteSwap;

int Xsize;

$/ *$ LSB (MSB) is first if $0 \times 0000(0 x \mathrm{ffff}) * /$

int Ysize;

$1 *$ \# of pixels in a line $* /$

int SampleSize;

$1 *$ \# of lines $* 1$

int RowColOrder;

$1 *$ \# of WORDs / pixel *l

int Yorigin;

$1 * 0000$ (ffff) if column (row) major *l

int Year;

$l * 0000$ (fff) if lower (upper) left $* l$

int Month;

int Day;

int Hour;

int Minute;

int Second;

unsigned Intensity0;

$1 *$ low temperature calib. intensity *

float Temperature0;

$1 *$ low temperature calib. temperature in C (2 WORDs) */

unsigned Intensity 1;

$1^{*}$ high temperature calib. intensity *I

float Temperature1;

$1 *$ high temperature calib. temperature in C ( 2 WORDs) */

float TargetGain;

int Revision;

I* (2 WORDs) *I

$/ *$ revision \# $(=0$ before $12 / 20 / 91$

$$
\begin{aligned}
& =1 \text { after } 12 / 20 / 91, \\
& =2 \text { after } 05 / 20 / 92) * \text { I }
\end{aligned}
$$

int NumFrames;

$l^{*}$ \# of frames stored in file ( $=1$ if no buffer board) $* /$

int UL-Row;

int UL_Col;

$/ *$ upper row (typically $=0) * i$

int LR_Row;

$1 *$ left column (typically $=0$ ) *l

int LR_Col;

$/ *$ lower row (typically $=127$ ) $* /$

int NumFramesSummed;

float FrameRate

$/ *$ right column (typically $=127$ ) $* /$

$l^{*}$ \# frames summed in each image *l

/* The following values added with Revision $2 * /$

float IntegrationTime;

$f^{*}$ frame rate in $\mathrm{Hz} *$ I

int BuffBrdNumFrames[12];

$/ *$.integration time in msec $* /$

int BuffBrdNumSkip[12];

$l^{*}$ up to 12 buffer board sub-sequence $* /$

$1 *$ frame values $* /$

$I^{*}$ up to 12 sub-sequence values for number of $* /$

$I^{*}$ frames skipped between each frame in the $* /$

int EmptyBuffer[HEADER_SIZE-55];

$/ *$ subsequences listed above. */

\}; 


\begin{tabular}{||l|l||}
\hline \multicolumn{2}{||l||}{ Instrument Description } \\
\hline Instrument Name & Echelle Grating Spectrometer \\
\hline Manufacturer & Lawrence Livermore National Laboratory \\
\hline Serial Number & 0001 \\
\hline Hardware Version & TBD \\
\hline $\begin{array}{l}\text { Operational Ranges } \\
\text { (Temp., Altitude, etc.) }\end{array}$ & $\begin{array}{l}\text { Sea level to } 30,000 \mathrm{ft} . \\
-30^{\circ} \mathrm{C} \text { to } 60^{\circ} \mathrm{C}\end{array}$ \\
\hline $\begin{array}{l}\text { Performance Parameters } \\
\text { (i.e., range of acquisition freqs.) }\end{array}$ & N/A \\
\hline $\begin{array}{l}\text { Normal mode of operation } \\
\text { Sampling frequency }\end{array}$ & $\begin{array}{l}\text { Infrared focal plane array (256 x 256) captures a frame of } \\
\text { spectral information. }\end{array}$ \\
\hline $\begin{array}{l}\text { Calibration Procedure } \\
1 \text { to } 100 \text { seconds }\end{array}$ \\
\hline Error Detection/Correction & $\begin{array}{l}\text { Software driven. Infrared array views several black bodies } \\
\text { at different temperatures. The frames are stored and used } \\
\text { to correct for pixel non-uniformity. }\end{array}$ \\
\hline $\begin{array}{l}\text { Data Recording Capabilities } \\
\text { (how long, how much) }\end{array}$ & None \\
\hline \hline
\end{tabular}

\begin{tabular}{||l|l||}
\hline \multicolumn{2}{|c||}{ (Fill out 1 Instrument Data - Raw Form for each named field) } \\
\hline Record Length & 164352 bytes \\
\hline Names of data fields & Image_Header, Image \\
\hline Record structure & 512 byte header followed by 163840 bytes of data. \\
\hline Recording Media & Solid-state disk \\
\hline
\end{tabular}




\begin{tabular}{||l|l||}
\hline \multicolumn{2}{|c|}{ Instrument Data - Raw Form } \\
\hline Name & \\
\hline Source (detector name) & Infrared focal plane array \\
\hline Form (analog, digital) & Digital \\
\hline How generated & $\begin{array}{l}\text { Output of each array pixel is digitized by a } \\
12 \text { bit A/D }\end{array}$ \\
\hline Units (counts, volts, etc.) & Counts \\
\hline Normal Range & 0 - 4095 \\
\hline Structure (8-, 16-, 32-bit, signed) & 16 bit word (pixel) \\
\hline $\begin{array}{l}\text { Internally Processed, e.g. averaged? } \\
\text { (If so, how?) }\end{array}$ & $\begin{array}{l}\text { Pixel non-uniformity corrected by applying } \\
\text { individual gain and offset based on calibra- } \\
\text { tion data, global gain, and offset available. }\end{array}$ \\
\hline Recording Media & Hard disk \\
\hline $\begin{array}{l}\text { Data that may be correlated with this data to } \\
\text { assess quality }\end{array}$ & None \\
\hline
\end{tabular}

\begin{tabular}{|l|l||}
\hline \multicolumn{2}{|c|}{ Data Record - Processed Form } \\
(Fill out 1 Instrument Data - Processed Form for each named field) \\
\hline Record Length & \\
\hline Names of data fields & \\
\hline Record structure & \\
\hline Recording Media & \\
\hline
\end{tabular}




\begin{tabular}{||l|l||}
\hline \multicolumn{2}{|c|}{ Instrument Data - Processed Form } \\
\hline Name & \\
\hline Source (detector name) & \\
\hline How generated (conversion process/algorithm) & $\begin{array}{l}\text { Raw spectral traces are pulled from frames cap- } \\
\text { tured by the focal plane. Traces are compared } \\
\text { with internal library of target chemicals. Alarm } \\
\text { tripped if match is found. }\end{array}$ \\
\hline Engineering Units & N/A \\
\hline Normal Range & N/A \\
\hline Uncertainty & N/A \\
\hline $\begin{array}{l}\text { Structure (8-, 16-, 32-bit, signed) } \\
\text { (Precision for floating point) }\end{array}$ & N/A \\
\hline $\begin{array}{l}\text { Data that may be correlated with this data to } \\
\text { assess quality }\end{array}$ & None \\
\hline
\end{tabular}

\begin{tabular}{||l|l||}
\hline \multicolumn{2}{|c||}{ Data Description } \\
\hline Targeted User(s) & \\
\hline How it will be used & \\
\hline Useful life of the data & \\
\hline Aircraft Data Available/Required & \\
\hline Meteorological Data Required & \\
\hline Forms in which data may be requested & \\
\hline $\begin{array}{l}\text { How data of interest may be identified } \\
\text { by users for extraction }\end{array}$ & \\
\hline
\end{tabular}




\subsection{Tracking Subsystem}

\begin{tabular}{||l|l||}
\hline \multicolumn{2}{|c|}{ Instrument Description } \\
\hline Instrument Name & Tracking Subsystem \\
\hline Manufacturer & TBD \\
\hline Serial Number & \\
\hline Hardware Version & 0 to $15,000 \mathrm{ft}$. \\
\hline $\begin{array}{l}\text { Operational Ranges } \\
\text { (Temp., Altitude, etc.) }\end{array}$ & Black and white TV or 3-5 $\mu \mathrm{m}$ FLIR with minimum \\
\hline $\begin{array}{c}\text { Performance Parameters } \\
\text { (i.e., range of acquisition freqs.) }\end{array}$ & FOV of approximately 2.5. \\
\hline $\begin{array}{l}\text { Normal mode of operation } \\
\text { Sampling frequency }\end{array}$ & $\begin{array}{l}1 . \text { Operator-aided acquisition } \\
2 . \text { Auto track }\end{array}$ \\
\hline Calibration Procedure & 60 fps \\
\hline Error Detection/Correction & TBD \\
\hline $\begin{array}{l}\text { Data Recording Capabilities } \\
\text { (how long, how much) }\end{array}$ & N/A \\
\hline \hline
\end{tabular}

\begin{tabular}{||l|l|}
\hline \multicolumn{2}{|c|}{ Data Record - Processed Form } \\
(Fill out 1 Instrument Data - Processed Form for each named field) \\
\hline Record structure & $\begin{array}{l}\text { Video - TV or FLIR imagery } \\
\text { RS170 } \\
\text { Annotated with azimuth, elevation, time, and trackgate }\end{array}$ \\
\hline Recording Media & SVHS or Hi-8-mm \\
\hline
\end{tabular}




\begin{tabular}{||l|l||}
\hline \multicolumn{2}{|c|}{ Instrument Data - Processed Form } \\
\hline Name & Tracking Subsystem \\
\hline Source (detector name) & TV / FLIR \\
\hline How generated (conversion process/algorithm) & $\begin{array}{l}\text { CCD - TV or } \\
\text { Staring FPA - FLIR }\end{array}$ \\
\hline Engineering Units & $3 \times 4$ Aspect ratio \\
\hline
\end{tabular}

\begin{tabular}{||l|l||}
\hline \multicolumn{2}{|c|}{ Data Description } \\
\hline Targeted User(s) & Operator identification of targets, track in fly-by \\
\hline How it will be used & Flight history, debriefing \\
\hline Useful life of the data & Life of video tape \\
\hline Aircraft Data Available/Required & Position and velocity \\
\hline Meteorological Data Required & Meteorological range (Visibility) \\
\hline Forms in which data may be requested & Video \\
\hline $\begin{array}{l}\text { How data of interest may be identified by } \\
\text { users for extraction }\end{array}$ & Symbology for azimuth, elevation, and time \\
\hline \hline
\end{tabular}

\subsection{Aerial Krypton Grab Sampler}

\begin{tabular}{||l|l||}
\hline \multicolumn{2}{|c||}{ Instrument Description } \\
\hline Instrument Name & Aerial Krypton Grab Sampler \\
\hline Manufacturer & Savannah River Technology Ctr. \\
\hline Serial Number & \\
\hline Hardware Version & 1 \\
\hline $\begin{array}{l}\text { Operational Ranges } \\
\text { (Temp., Altitude, etc.) }\end{array}$ & $\begin{array}{l}\text { Storage Temp: }-20^{\circ} \mathrm{C} \text { to } 70^{\circ} \mathrm{C} \\
\text { Operating Temp: } 0^{\circ} \mathrm{C} \text { to } 40^{\circ} \mathrm{C} \\
\text { Operating Alt: } 0 \text { to } 15,000 \mathrm{ft}\end{array}$ \\
\hline
\end{tabular}




\begin{tabular}{||l|l||}
\hline \multicolumn{2}{|c||}{ Instrument Description (contd) } \\
\hline $\begin{array}{c}\text { Performance Parameters } \\
\text { (i.e., range of acquisition freqs.) }\end{array}$ & $\begin{array}{l}\text { Air Flow Rate: } 10 \text { liters/min } \pm 15 \% \\
1 \text { to } 12 \text { samples }\end{array}$ \\
\hline $\begin{array}{l}\text { Normal mode of operation } \\
\text { Collection initiated by operator. Sample sequencing and } \\
\text { instrument control after initiation is automatic. }\end{array}$ \\
\hline Sampling frequency & 1 sample every 10 minutes \\
\hline Calibration Procedure & $\begin{array}{l}\text { Air flow rates calibrated against a primary standard or } \\
\text { against a NIST traceable standard. }\end{array}$ \\
\hline $\begin{array}{l}\text { Error Detection/Correction } \\
\text { Collection parameters and instrument state of health } \\
\text { monitoring. }\end{array}$ \\
\hline $\begin{array}{c}\text { Data Recording Capabilities } \\
\text { (how long, how much) }\end{array}$ & $\begin{array}{l}\text { Collection parameters, state of health monitoring for } \\
\text { duration of mission. }\end{array}$ \\
\hline
\end{tabular}

\begin{tabular}{||l|l||}
\hline \multicolumn{2}{|c||}{ Data Record - Raw Form } \\
\hline Record Length & \\
\hline Names of data fields 1 Instrument Data - Raw Form for each named field) \\
\hline Record structure & \\
\hline Recording Media & \\
\hline
\end{tabular}

\begin{tabular}{||l|l||}
\hline \multicolumn{2}{|c|}{ Instrument Data - Raw Form } \\
\hline Name & Sampler Operation Data \\
\hline Source (detector name) & Aerial Krypton Grab Sampler \\
\hline Form (analog, digital) & Digital \\
\hline How generated & From sampler operation \\
\hline Units (counts, volts, etc.) & N/A \\
\hline Normal Range & N/A \\
\hline Structure (8-, 16-, 32-bit, signed) & N/A \\
\hline
\end{tabular}




\begin{tabular}{||l|l||}
\hline \multicolumn{2}{|c||}{ Instrument Data - Raw Form (contd) } \\
\hline $\begin{array}{l}\text { Internally Processed, e.g., averaged? } \\
\text { (If so, how?) }\end{array}$ & N/A \\
\hline Recording Media & Solid state memory \\
\hline Data that may be correlated with this data to assess quality & N/A \\
\hline
\end{tabular}

\begin{tabular}{||l|l||}
\hline \multicolumn{2}{|c|}{ Data Record - Processed Form } \\
(Fill out 1 Instrument Data - Processed Form for each named field) \\
\hline Record Length & TBD \\
\hline Names of data fields & TBD \\
\hline Record structure & TBD \\
\hline Recording Media & \\
\hline
\end{tabular}

\begin{tabular}{||l|l||}
\hline \multicolumn{2}{|c|}{ Instrument Data - Processed Form } \\
\hline Name & Sampler Operation Data \\
\hline Source (detector name) & Aerial Krypton Grab Sampler \\
\hline How generated (conversion process/algorithm) & N/A \\
\hline Engineering Units & N/A \\
\hline Normal Range & N/A \\
\hline Uncertainty & N/A \\
\hline $\begin{array}{l}\text { Structure (8-, 16-, 32-bit, signed) } \\
\text { (Precision for floating point) }\end{array}$ & N/A \\
\hline Data that may be correlated with this data to assess quality & N/A \\
\hline
\end{tabular}




\begin{tabular}{||l|l||}
\hline \multicolumn{2}{|c|}{ Data Description } \\
\hline Targeted User(s) & DOE AN \\
\hline How it will be used & Target Analysis \\
\hline Useful life of the data & Unlimited \\
\hline Aircraft Data Available/Required & Position location during sample collection. \\
\hline Meteorological Data Required & $\begin{array}{l}\text { Temperature, humidity, barometric pressure, } \\
\text { wind direction and speed, elevation of sample } \\
\text { collection above sea level. Data to be collected } \\
\text { periodically throughout sampling period. }\end{array}$ \\
\hline Forms in which data may be requested & Diskette \\
\hline $\begin{array}{l}\text { How data of interest may be identified by users } \\
\text { for extraction. }\end{array}$ & N/A \\
\hline
\end{tabular}

\subsection{Intrinsic Ge Detector}

\begin{tabular}{||l|l||}
\hline \multicolumn{2}{|c|}{ Instrument Description } \\
\hline Instrument Name & Intrinsic Ge Detector \\
\hline Manufacturer & EG\&G ORTEC \\
\hline Serial Number & $?$ \\
\hline Hardware Version & $?$ \\
\hline $\begin{array}{l}\text { Operational Ranges } \\
\text { (Temp., Altitude, etc.) }\end{array}$ & $?^{\circ} \mathrm{F}$ to $90^{\circ} \mathrm{F}$ \\
0 to $30,000 \mathrm{ft}$ \\
\hline $\begin{array}{l}\text { Performance Parameters } \\
\text { (i.e., range of acquisition freqs.) }\end{array}$ & Sensitive from $40 \mathrm{KeV}$ to $\sim 4000 \mathrm{KeV}$ \\
\hline Normal mode of operation & \\
\hline Sampling frequency & 10 seconds \\
\hline Calibration Procedure & Manual with a mixed standard radioactive source. \\
\hline Error Detection/Correction & None \\
\hline $\begin{array}{l}\text { Data Recording Capabilities } \\
\text { (how long, how much) }\end{array}$ & $\begin{array}{l}120 \text { spectra, } 8000 \text { channels each. } \\
\text { Approximately } 2 \text { hrs. of operation. }\end{array}$ \\
\hline
\end{tabular}




\begin{tabular}{||l|l|}
\hline \multicolumn{2}{|c|}{ (Fill out 1 Instrument Data - Raw Form for each named field) } \\
\hline Record Length & $16 \bullet 32 \mathrm{~KB}$ \\
\hline Names of data fields & TBD \\
\hline Record structure & TBD \\
\hline Recording Media & RAM with battery backup \\
\hline
\end{tabular}

\begin{tabular}{||l|l||}
\hline \multicolumn{2}{|c|}{ Instrument Data - Raw Form } \\
\hline Name & Intrinsic Ge Detector \\
\hline Source (detector name) & $\sim 120 \%$ EG\&G Ge crystal \\
\hline Form (analog, digital) & Analog \\
\hline How generated & $\begin{array}{l}\text { Direct result of amplified current pulse gen- } \\
\text { erated by gamma interaction with Ge crystal. }\end{array}$ \\
\hline Units (counts, volts, etc.) & Volts \\
\hline Normal Range & .002 V to 10V \\
\hline Structure (8-, 16-, 32-bit, signed) & N/A \\
\hline $\begin{array}{l}\text { Internally Processed, e.g. averaged? } \\
\text { (ff so, how?) }\end{array}$ & $\begin{array}{l}\text { Calibration data collected from a mixed } \\
\text { radioisotope standard source. }\end{array}$ \\
\hline Recording Media & $\begin{array}{l}\text { Data that may be correlated with this } \\
\text { data to assess quality }\end{array}$
\end{tabular}

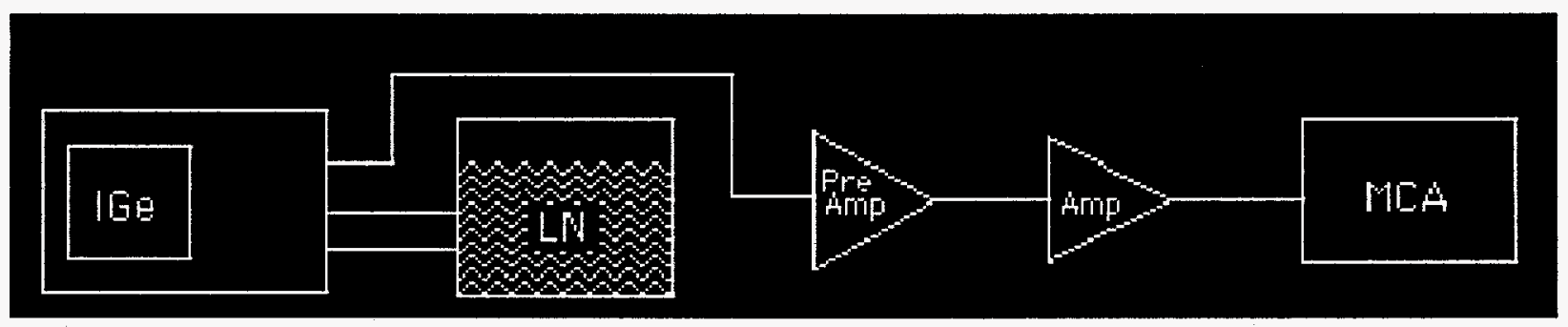




\begin{tabular}{||l|l||}
\hline \multicolumn{2}{|c|}{ Data Record - Processed Form } \\
(Fill out 1 Instrument Data - Processed Form for each named field) \\
\hline Record Length & $16-32 \mathrm{~Kb}$ \\
\hline Names of data fields & TBD \\
\hline Record structure & TBD \\
\hline Recording Media & Battery backed static RAM \\
\hline
\end{tabular}

\begin{tabular}{||l|l||}
\hline \multicolumn{2}{|c|}{ Instrument Data - Processed Form } \\
\hline Name & Gamma Spectrum \\
\hline Source (detector name) & $120 \%$ IGe \\
\hline $\begin{array}{l}\text { How generated (conversion } \\
\text { process/algorithm) }\end{array}$ & Result of Gamma radiation \\
\hline Engineering Units & $\begin{array}{l}\text { Counts / Energy chnl } \\
\text { Pulse height histogram }\end{array}$ \\
\hline Normal Range & 0 to 8000 chnis each containing a maximum of 2232 counts. \\
\hline Uncertainty & \pm 1.5 Chnls \\
\hline $\begin{array}{l}\text { Structure (8-, 16-, 32-bit, signed) } \\
\text { (Precision for floating point) }\end{array}$ & 32 bit unsigned / chnl \\
\hline $\begin{array}{l}\text { Data that may be correlated with } \\
\text { this data to assess quality }\end{array}$ & $\begin{array}{l}\text { Calibration spectra from standard source + time of day, } \\
\text { airspeed, altitude, temperature, humidity }\end{array}$ \\
\hline
\end{tabular}

\begin{tabular}{||l|l||}
\hline \multicolumn{2}{|c||}{ Data Description } \\
\hline Targeted User(s) & \\
\hline How it will be used & \\
\hline Useful life of the data & \\
\hline Aircraft Data Available/Required & \\
\hline Meteorological Data Required & \\
\hline Forms in which data may be requested & \\
\hline $\begin{array}{l}\text { How data of interest may be identified } \\
\text { by users for extraction }\end{array}$ & $\begin{array}{l}\text { Consultation with instrument developers in 1st version. } \\
\text { Eventually data of interest will be automatically provided. }\end{array}$ \\
\hline
\end{tabular}




\subsection{Aircraft Data}

\subsection{Outside Air Temperature System}

\begin{tabular}{||l|l||}
\hline \multicolumn{2}{|c|}{ Instrument Description } \\
\hline Instrument Name & Outside Air Temperature Gauge \\
\hline Manufacturer & Unknown \\
\hline Serial Number & Unknown \\
\hline Hardware Version & Unknown \\
\hline $\begin{array}{l}\text { Operational Ranges } \\
\text { (Temp., Altitude, etc.) }\end{array}$ & $-50^{\circ} \mathrm{C}$ to $50^{\circ} \mathrm{C}$ \\
\hline $\begin{array}{l}\text { Performance Parameters } \\
\text { (i.e., range of acquisition freqs.) }\end{array}$ & $\begin{array}{l}\text { Indicates OAT uncorrected for air compression } \\
\text { effects. }\end{array}$ \\
\hline $\begin{array}{l}\text { Normal mode of operation } \\
\text { Continuous }\end{array}$ \\
\hline Sampling frequency & $\begin{array}{l}\text { Compared against reported OAT statically on } \\
\text { deck. }\end{array}$ \\
\hline $\begin{array}{l}\text { Calibration Procedure } \\
\text { None }\end{array}$ \\
\hline Error Detection/Correction \\
\hline $\begin{array}{l}\text { Data Recording Capabilities } \\
\text { (how long, how much) }\end{array}$ & No automated recording \\
\hline
\end{tabular}

\subsection{Garmin GPS 100}

\begin{tabular}{||l|l||}
\hline \multicolumn{2}{|c|}{ Instrument Description } \\
\hline Instrument Name & GPS 100 \\
\hline Manufacturer & Garmin \\
\hline Serial Number & \\
\hline
\end{tabular}




\begin{tabular}{||l|l||}
\hline \multicolumn{2}{|c||}{ Instrument Description (contd) } \\
\hline Hardware Version & \\
\hline Operational Ranges & $-15^{\circ} \mathrm{C}$ to $70^{\circ} \mathrm{C}$ operating \\
(Temp., Altitude, etc.) & $-40^{\circ} \mathrm{C}$ to $70^{\circ} \mathrm{C}$ storage \\
& Humidity $95 \%$ non-condensing \\
\hline Performance Parameters & Receiver: \\
(i.e., range of acquisition freqs.) & tracking up to 8 satellites \\
& Acquisition time: \\
& 2 minutes $2 \mathrm{D}$ \\
& 2.5 minutes $3 \mathrm{D}$ \\
& Update rate: 1 sec. \\
& Accuracy: \\
& Position: $15 \mathrm{~m}$ RMS \\
& Velocity: 0.1 knots RMS \\
& Dynamics: \\
& 695 knots velocity \\
& $3 \mathrm{~g}$ dynamics \\
\hline Normal mode of operation & \\
\hline Sampling frequency & 1 second update rate \\
\hline Calibration Procedure & \\
\hline Error Detection/Correction & \\
\hline Data Recording Capabilities & \\
(how long, how much) & \\
\hline \hline
\end{tabular}

\subsubsection{Garmin GPS 100 NMBA 0183 Output Interface}

\subsubsection{Electrical Interface}

The output signals conform to NMEA 0183 . Data is generated at 4800 baud with each character containing 8 data bits, one stop bit, and no parity. There are approximately 3 milliseconds between character starts. 


\subsubsection{General Output Format}

The NMEA 0183 sentences output by the GPS 100 in a single "frame" are:

- RMC

- RMB

- ROO

- WPL - (one for every waypoint identifier in the ROC sentence)

- GLL

- PGRMA

- XTE

- BWC

The GPS 100 NMEA 0183 frame is repeated every two seconds. The format of the sentences contained within each frame are shown below.

RMC Sentence Format (GPS and Transit Specific)

\$GPRMC,HHMMSS,A,DDMM.MM,N,DDDMM,MM,W,XXX.X,XXX.X,DDMMYY,XXX.X,B*XX 123

45

678

9

10

11

1. Time (UTC)

2. Position valid $(A=$ valid, $V=$ invalid $)$

3. Latitude at UTC time (degrees and minutes)

4. Latitude direction $(\mathrm{N}=$ north, $\mathrm{S}=$ south $)$

5. Longitude at UTC time (degrees and minutes)

6. Longitude direction $(\mathrm{E}=$ east, $\mathrm{W}=$ south $)$

7. Speed over ground (knots) 
8. Course over ground or track (degrees, true)

9. Date (day, month, year)

10. Magnetic variation (degrees)

11. Magnetic variation direction $(\mathrm{E}=$ east, $\mathrm{W}=$ west $)$

12. Checksum

\section{RMB Sentence Format (Generic Navigation Information)}

\$GPRMB,A,XX.XX,L,CCCC,CCCC,DDMM.MM,N,DDDMM.MM,W,XXX.X,XXX.X,XXX.X,A*XX
12
34
56
78
$9 \quad 10$
11
$\begin{array}{lll}12 & 13 & 14\end{array}$

1. Position valid $(\mathrm{A}=$ valid, $\mathrm{V}=$ invalid $)$

2. Cross track error (nautical miles)

3. Direction to steer ( $\mathrm{L}=$ left, $\mathrm{R}=$ right)

4. Origin waypoint identifier

5. Destination waypoint identifier

6. Destination latitude (degrees and minutes)

7. Destination latitude direction $(\mathrm{N}=$ north, $\mathrm{S}=$ south)

8. Destination longitude (degrees and minutes)

9. Destination longitude direction $(\mathrm{E}=$ east, $\mathrm{W}=$ west $)$

10. Range from present position to destination waypoint (nautical miles)

11. Bearing from present position to destination waypoint (degrees, true)

12. Closing velocity to destination waypoint (knots)

13. Arrival flag ( $A=$ arrival, $\mathrm{V}=$ not arrival)

14. Checksum 
ROO Sentence Format (Route Number 0)

\$GPRO0, CCCC, CCCC, CCCC, CCCC, CCCC, CCCC, $\mathrm{CCCC}, \mathrm{CCCC}, \mathrm{CCCC}$, , , , , ${ }^{\mathrm{XX}}$

$\begin{array}{llllllllll}1 & 2 & 3 & 4 & 5 & 6 & 7 & 8 & 9 & 10\end{array}$

1-9. Waypoint identifiers of route in sequence

10. Checksum

WPL Sentence Format (Waypoint Location)

\$GPWFL,DDMM.MM,N,DDDMM.MM,W,CCCC*XX

$\begin{array}{lllll}1 & 2 & 3 & 4 & 5\end{array}$

1. Waypoint latitude (degrees and minutes)

2. Waypoint latitude direction $(\mathrm{N}=$ north, $\mathrm{S}=$ south)

3. Waypoint longitude (degrees and minutes)

4. Waypoint longitude direction ( $\mathrm{E}=$ east, $\mathrm{W}=$ west $)$

5. Waypoint identifier

6. Checksum

GLL Sentence Format (Geographical)

\$GPGLL,DDMM.MM,N,DDDMM.MM,W*XX

$1 \quad 23 \quad 45$

1. Present latitude (degrees and minutes)

2. Present latitude direction ( $N=$ north, $S=$ south)

3. Present longitude (degrees and minutes)

4. Present longitude direction ( $\mathrm{E}=$ east, $\mathrm{W}=$ west)

5. Checksum 
PGRMA Sentence Format (Proprietary GARMIN Altitude)

\$GPGLL,XXXXX,f, X*XX

$1 \quad 234$

1. Present altitude (feet)

2. Units ( $f=f e e t)$

3. Position fix dimensions ( $2=$ user altitude, $3=$ GPS altitude)

4. Checksum

XTE Sentence Format (Cross-Track Error, Measured)

\$GPXTE,A,A,XX.XX,L, N*XX

$123 \quad 456$

1. Position valid $(A=$ valid,$V=$ invalid $)$

2. Position valid $(A=$ valid, $V=$ invalid $)$

3. Cross-track error (nautical miles)

4. Direction to steer $(\mathrm{L}=$ left, $\mathrm{R}=$ right $)$

5. Units (nautical miles)

6. Checksum

BWC Sentence Format (Bearing and Distance to Waypoint, Great Circle)

\$GPBWC,HHMMSS,DDMM.MM,N,DDDMM.MM,W,XXX.X,T,XXX.X,M,XXX.X,N,CCC*XX

$\begin{array}{lllllllllll}1 & 2 & 3 & 4 & 5 & 6 & 78 & 9 & 10 & 11 & 12\end{array}$

1. Time (UTC)

2. Waypoint latitude (degrees and minutes)

3. Waypoint latitude direction $(\mathrm{N}=$ north, $\mathrm{S}=$ south)

4. Waypoint longitude (degrees and minutes)

5. Waypoint longitude direction ( $E=$ east, $W=$ west $)$ 
6. Bearing from present position to waypoint (degrees, true)

7. Units (true degrees)

8. Bearing from present position to waypoint (degrees, magnetic)

9. Units (magnetic degrees)

10. Distance from present position to waypoint (nautical miles)

11. Units (nautical miles)

12. Waypoint identifier

13. Checksum

\begin{tabular}{||l|l||}
\hline \multicolumn{2}{|c|}{ Data Description } \\
\hline Targeted User(s) & Pod integrators, data analysts \\
\hline How will it be used & Position and attitude of aircraft \\
\hline Useful life of the data & Unlimited \\
\hline Aircraft Data Available/Required & N/A \\
\hline Meteorological Data Required & N/A \\
\hline Forms in which data may be requested & Unknown \\
\hline $\begin{array}{l}\text { How data of interest may be identified } \\
\text { by users for extraction }\end{array}$ & $?$ \\
\hline
\end{tabular}

\subsection{P3 Inertial Navigation System}

\begin{tabular}{||l|l||}
\hline \multicolumn{2}{|c|}{ Instrument Description } \\
\hline Instrument Name & LTN-72 Inertial \\
\hline Manufacturer & Litton Aero Products \\
\hline Serial Number & N/A \\
\hline Hardware Version & Standard P-3 fleet version \\
\hline
\end{tabular}




\begin{tabular}{||l|l||}
\hline \multicolumn{2}{|c||}{ Instrument Description (contd) } \\
\hline $\begin{array}{c}\text { Operational Ranges } \\
\text { (Temp., Altitude, etc.) }\end{array}$ & $\begin{array}{l}\text { Warm up to nominal temperature - } 15 \text { minutes } \\
0 \text { to } 500 \text { knots } \\
0 \text { to } 40,000 \mathrm{ft}\end{array}$ \\
\hline $\begin{array}{l}\text { Performance Parameters } \\
\text { (i.e., range of acquisition freqs.) }\end{array}$ & \\
\hline Normal mode of operation & $\begin{array}{l}\text { Inertial Mode } \\
\text { Attitude only as backup if inertial dumps in flight }\end{array}$ \\
\hline Sampling frequency & $24 \mathrm{~Hz}$ \\
\hline $\begin{array}{l}\text { Calibration Procedure } \\
\text { Error Detection/Correction }\end{array}$ & $\begin{array}{l}\text { US Navy Maintenance as required } \\
\text { Maximum allowable error 1NM/hr }\end{array}$ \\
\hline $\begin{array}{l}\text { Data Recording Capabilities } \\
\text { (how long, how much) }\end{array}$ & Post flight and in-flight by navigator \\
\hline
\end{tabular}

\begin{tabular}{||l|l||}
\hline \multicolumn{2}{|c||}{ (Fill out 1 Instrument Data - Raw Form for each named field) } \\
\hline Record Length & \\
\hline Names of data fields & $\begin{array}{l}\text { True HDG, N-S Vel, E-W Vel, Pos LAT, Pos LON, WPT } \\
\text { LAT, WPT LON, Pitch, Roll, Drift Angle, TAS, MAG } \\
\text { HDG }\end{array}$ \\
\hline Record structure & \\
\hline Recording Media & \\
\hline
\end{tabular}

\subsubsection{Litton Inertial Navigation System Data Description}

Each aircraft has dual independent systems. The following excerpt describes data generated by the Litton Inertial Navigation System:

In the P-3B only, waypoint words are normally coded "no computed data" unless 1) the operator selects RMT and WPT on the CDD or 2) the operator inserts waypoint latitude or longitude. When the operator selects RMT or WPT, all eighteen waypoint LAT/LON words are output with valid data, in one 64-word cycle. The output then returns to transmission of no computed data in the waypoint words. When the operator inserts a Waypoint Latitude or Longitude, the INS utilizes the next available 
64-word cycle to transmit the inserted valid data in the appropriately numbered waypoint words. The output data then returns to transmission of no computed data.

In the data field, bit 32 is odd parity, bits 31 and 30 are the sign matrix, and bit 29 is the MSb. The label field comprises the first 8 bits and is in accordance with ARINC 419 .

\subsubsection{Output Bus 2 (JID-19 through 23)}

Output Bus 2 outputs a combination of binary, BCD and packed words that is aircraft-dependent. The relationship is as follows:

- Binary on all aircraft: Velocity north, velocity east, roll, pitch, true airspeed, drift angle, Mag HDG, and waypoint data.

- Binary on all aircraft except SP-3: BCD on SP-3: True heading, latitude, and longitude.

- BCD on all aircraft: distance to go, and ground speed.

- Packed words on all aircraft: distance traveled, waypoint counter, INS status, and AMC out 1 , 2,3 , and 4 .

\subsubsection{Binary Data Description}

\begin{tabular}{|l|c|l|l|c|}
\hline \multicolumn{1}{|c|}{ Parameter } & Label B & \multicolumn{1}{c|}{ Units } & \multicolumn{1}{c|}{ MSB } & $\begin{array}{c}\text { Significant } \\
\text { Bits }\end{array}$ \\
\hline True HDG & 014 & Radians & pi & 12 \\
\hline N-S Vel & 066 & Ft/Sec & 540.01664 & 14 \\
\hline E-W Vel & 067 & Ft/Sec & 540.01664 & 14 \\
\hline Pos LAT & 010 & Radians & $\mathrm{pi} / 2$ & 17 \\
\hline Pos LON & 011 & Radians & $\mathrm{pi} / 2$ & 17 \\
\hline WPT LAT & 133 & Radians & $\mathrm{pi} / 2$ & 17 \\
\hline WPT LON & 133 & Radians & $\mathrm{pi} / 2$ & 17 \\
\hline Pitch & 135 & Radians & $\mathrm{pi} / 2$ & 12 \\
\hline Roll & 017 & Radians & $\mathrm{pi} / 2$ & 12 \\
\hline Drift Angle & 006 & Radians & $\mathrm{pi} / 2$ & 12 \\
\hline TAS & 033 & Knots & 500 & 12 \\
\hline MAG HDG & 114 & Radians & $\mathrm{pi} / 2$ & 12 \\
\hline
\end{tabular}




\begin{tabular}{||l|l||}
\hline \multicolumn{2}{|c|}{ Instrument Data - Raw Form } \\
\hline Name & LTN-72 Inertial \\
\hline Source (detector name) & Internal \\
\hline Form (analog, digital) & Binary \\
\hline How generated & ARINC 419 Format \\
\hline Units (counts, volts, etc.) & \\
\hline Normal Range & \\
\hline Structure (8-, 16-, 32-bit, signed) & \\
\hline $\begin{array}{l}\text { Internally Processed, e.g. averaged? } \\
\text { If so, how?) }\end{array}$ & \\
\hline Recording Media & GPS position, groundspeed \\
\hline $\begin{array}{l}\text { Data that may be correlated with this } \\
\text { data to assess quality }\end{array}$ & \\
\hline
\end{tabular}

\begin{tabular}{||l|l||}
\hline \multicolumn{2}{|c|}{ Data Record - Processed Form } \\
(Fill out 1 Instrument Data - Processed Form for each named field) \\
\hline Record Length & \\
\hline Names of data fields & \\
\hline Record structure & \\
\hline Recording Media & \\
\hline
\end{tabular}

\begin{tabular}{||l|l||}
\hline \multicolumn{2}{|c|}{ Instrument Data - Processed Form } \\
\hline Name & \\
\hline Source (detector name) & \\
\hline How generated (conversion process/algorithm) & \\
\hline Engineering Units & \\
\hline Normal Range & \\
\hline
\end{tabular}




\begin{tabular}{||l|l||}
\hline \multicolumn{2}{|c||}{ Instrument Data - Processed Form (contd) } \\
\hline Uncertainty & \\
\hline $\begin{array}{l}\text { Structure (8-, 16-, 32-bit, signed) } \\
\text { (Precision for floating point) }\end{array}$ & \\
\hline $\begin{array}{l}\text { Data that may be correlated with this data to assess } \\
\text { quality }\end{array}$ & \\
\hline
\end{tabular}

\begin{tabular}{||l|l||}
\hline \multicolumn{2}{|c||}{ Data Description } \\
\hline Targeted User(s) & \\
\hline How will it be used & \\
\hline Useful life of the data & \\
\hline Aircraft Data Available/Required & \\
\hline Meteorological Data Required & \\
\hline Forms in which data may be requested & \\
\hline $\begin{array}{l}\text { How data of interest may be identified } \\
\text { by users for extraction }\end{array}$ & \\
\hline
\end{tabular}




\section{Distribution}

No. of

Copies

OFFSITE

12 DOE/Office of Scientific and Technical Information

Michael F. O'Connell

Office of Arms Control and

Nonproliferation

U.S. Department of Energy

1000 Independence Avenue

Washington, DC 20585

Ralph Hastings

NN-20, GA-033

Office of Research and Development

U.S. Department of Energy

1000 Independence Avenue

Washington, DC 20585
No. of

Copies

ONSITE

22 Pacific Northest Laboratory

K. K. Anderson K7-34

M. J. Burford K7-28

J. C. Cordero K7-28

R. A. Gimenez K7-28

J. A. Hucks K7-28

R. W. Jordan K7-28

J. J. Jou K7-22

T. F. Lundeen K6-84

W. D. Meitzler K7-22

R. B. Melton K7-02

J. W. Nageley K7-10

B. A. Roberts K6-48

T. L. Tran K7-28

H. A. Undem K6-48

M. S. Vorce K1-96

R. A. Warner K6-48

Publishing Coordination

Technical Report Files (5)

Distr.1 